\title{
Die Belagerung Freibergs 1643 als Beispiel der Rolle Kursachsens in der Endphase des Dreißigjährigen Krieges
}

\author{
von \\ TORSTEN SCHWENKE
}

Jahreswechsel 1642/43: ${ }^{1}$ Der Dreißigjährige Krieg geht in sein mittlerweile fünfundzwanzigstes Jahr. Kurz nach der zweiten Schlacht bei Breitenfeld und der Einnahme des sächsischen Handelszentrums Leipzig durch die schwedische Armee im Herbst 1642 fokussierte sich das Kriegstheater jetzt auf die Bergstadt Freiberg. Entgegen aller Erwartungen wehrte sich hier eine relativ kleine Besatzung kursächsischer Truppen mit Unterstützung der ansässigen Bürgerschaft recht erfolgreich gegen die schwedische Hauptarmee unter dem als geschickten Strategen und Festungsbezwinger bekannten Feldmarschall Lennart Torstensson (1603-1651). ${ }^{2}$ Obwohl die Angreifer die Stadt mit aller härte, macht und gewaldt [...] attaquiret, bloquiret, angefallen, beschoßn, gesturmet ond allrseits ond orths beängstiget hatten, gelang es den Verteidigern, diesem hochmüthigen vndt blutdürstigen Feinde ond seinen grawsamen attentaten ${ }^{3}$ vom 6. Januar bis zum 27. Februar $1643 \mathrm{zu}$ widerstehen und damit die Stadt so lange zu halten, bis die anrückende kaiserliche Entsatzarmee die schwedischen Einheiten zum Rückzug nötigte. Dadurch feierten die kaiserlichen und kursächsischen Farben in einer Zeit der Niederlagen einen unerwarteten Erfolg, der schon von den Zeitgenossen gelobt, später ein wesentlicher Teil städtischer Identität und kollektiver Erinnerung der Freiberger Bürgerschaft werden sollte. ${ }^{4}$

1 Alle Daten werden nach dem modernen Kalender angegeben. Jedoch soll darauf hingewiesen werden, dass aufgrund des zeitgenössischen Festhaltens Kursachsens und anderer protestantischer Territorien des Reiches sowie auch Schwedens am julianischen Kalender in den Quellenverweisen Daten nach altem Kalender aufgeführt sein können, welche im Folgenden mit dem Zusatz [julian.] gekennzeichnet werden.

2 Zur Person Torstenssons: Jörg-Peter FindeIsen, Der Dreißigjährige Krieg. Eine Epoche in Lebensbildern, Graz/Wien/Köln 1998, S. 437-442.

3 Stadtarchiv Freiberg (im Folgenden: StadtA Freiberg), Rep. AA, Abt. IX, Sekt. I, Nr. 172/2, unpaginiert, Schreiben des Exulanten Hieronymus Wesner vom 22. April 1643 [julian.] an den Rat zu Freiberg.

4 Zur Besonderheit der Freiberger Erinnerungskultur vgl. Ulrich Rosseaux, Das historische Jubiläum als kommunales Ereignis. Die Entstehung und Verbreitung städtischer Jubiläen in der Frühen Neuzeit, in: Ulrich Rosseaux/Wolfgang Flügel/Veit Damm (Hg.), Zeitrhythmen und performative Akte in der städtischen Erinnerungskultur zwischen Früher Neuzeit und Gegenwart (Bausteine aus dem Institut für Sächsische Geschichte und Volkskunde 6), Dresden 2005, S. 93-111, hier S. 108; zeitgenössisch zu 
Lange Zeit hat die historische Forschung jedoch dieser Endphase des Dreißigjährigen Krieges ${ }^{5}$ eine randständige Rolle beigemessen. Vielmehr konzentrierte sie sich zunächst auf den Zeitraum des Krieges, in der die scheinbar großen Protagonisten wie Gustav II. Adolf von Schweden (1594-1632) oder Albrecht von Wallenstein (1583-1634) die Szenerie beherrschten, oder das Augenmerk lag auf dem Friedensschluss in Münster und Osnabrück. ${ }^{6}$ Ähnliches kann auch mit Blick auf die sächsische Landesgeschichtsschreibung konstatiert werden. Hier fehlt es bisher nicht nur an einer modernen Überblicksdarstellung7 zum Dreißigjährigen Krieg, sondern auch an umfangreichen wie tiefgründigen Einzelstudien zur Rolle Kursachsens. Lediglich die Studie Frank Müllers zur kursächsischen Politik in der Frühphase des Krieges bildet hierbei eine Ausnahme. ${ }^{8}$ Dabei erscheint es gerade

den Jubiläumsfeiern beispielsweise: Freybergische Stadt=Jubel=Acta oder Nachricht von dem [...] feyerlichst begangenen Befreyungs-Jubel-Fest [...], Freiberg 1743; Die Feier des 17. Februar 1843 und des 11. und 12. August 1844 zu Freiberg, Freiberg 1844; grundlegend zum historischen Jubiläum: Winfried MüLler (Hg.), Das historische Jubiläum. Genese, Ordnungsleistung und Inszenierungsgeschichte eines institutionellen Mechanismus (Geschichte. Forschung und Wissenschaft 3), Münster 2004.

5 Vgl. zur klassischen Einteilung des Kriegsverlaufes: JohannEs Burkhardt, Der Dreißigjährige Krieg, Frankfurt am Main 1992, S. 16 f.; so beispielsweise bei GERHARD Schormann, Der Dreißigjährige Krieg, Göttingen ${ }^{32004}$, S. 25-59; in leichter Anpassung: Johannes Arndt, Der Dreißigjährige Krieg 1618-1648, Stuttgart 2009, S. 59-175. Andere Setzung der Zäsuren z. B. bei Georg Schmidt, Der Dreißigjährige Krieg, München 1999, S. 28-82; Christoph Kampmann, Europa und das Reich im Dreißigjährigen Krieg. Geschichte eines europäischen Konflikts, Stuttgart 2008. - Im Hinblick auf Kursachsen sind jedoch auch andere Einteilungen denkbar. Vgl. Katrin Keller, Das „eigentliche wahre und große Friedensfest... im ganzen Sachsenlande“. Kursachsen von 1648 bis 1650, in: Heinz Duchhardt (Hg.), Der Westfälische Friede. Diplomatie politische Zäsur - kulturelles Umfeld - Rezeptionsgeschichte (Historische Zeitschrift, Beihefte N. F. 26), München 1998, S. 661-677, hier S. 663.

6 Vgl. Kampmann, Europa und das Reich (wie Anm. 5), S. 5; Frank Kleinehagenbrock, Das Alte Reich als europäisches Schlachtfeld. Der Schwedisch-Französische Krieg 1635-1648, in: Peter C. Hartmann/Florian Schuller (Hg.), Der Dreißigjährige Krieg. Facetten einer folgenreichen Epoche, Regensburg 2010, S. 129-145, hier S. 129; Geoffrey Parker, Der Dreißigjährige Krieg, New York/Frankfurt am Main 1987, S. 15. Des Weiteren zur Französisch-Schwedischen Phase des Krieges unter anderen: Jenny Öhman, Der Kampf um den Frieden. Schweden und der Kaiser im Dreißigjährigen Krieg (Militärgeschichtliche Dissertationen österreichischer Universitäten 16), Wien 2005; William P. Guthrie, The later Thirty Years War. From the Battle of Wittstock to the Treaty of Westphalia (Contributions in Military Studies 222), Westport/ London 2003; ERnst HöFER, Das Ende des Dreißigjährigen Krieges. Strategie und Kriegsbild, Köln/Weimar/Wien 1997; Karsten Ruppert, Die kaiserliche Politik auf dem Westfälischen Friedenskongreß (1643-1648), Münster 1979.

7 Ein Versuch der Auflösung dieses Desiderats mit Blick auf das kursächsische Militär in weiten Teilen mit klassisch militärgeschichtlicher Ausrichtung bei Roland SEnNEwald, Das kursächsische Heer im Dreißigjährigen Krieg 1618-1648, Berlin 2013; allgemeiner als positivistische Verlaufsgeschichte: Christian Kunath, Kursachsen im Dreißigjährigen Krieg, Dresden 2011.

8 Vgl. Frank Müller, Kursachsen und der Böhmische Aufstand 1618-1622 (Schriftenreihe der Vereinigung zur Erforschung der Neueren Geschichte 23), Münster 1997. Jedoch Ansätze und Vertiefungen in Aufsatzform unter anderem konzentriert in: 
wegen der traditionellen Stellung Sachsens im politischen und konfessionellen Gefüge des Alten Reiches ${ }^{9}$ von besonderem Interesse, auch das Agieren des Kurstaates in jenem Zeitraum intensiver in den Blick zu nehmen, als der Dreißigjährige Krieg nochmals an Komplexität gewann und Sachsen einen der wesentlichen Kriegsschauplätze darstellte. So wird im Folgenden versucht, die Rolle Kursachsens sowie auch die Art der Kriegsführung während dieser Kriegsphase anhand der Belagerung Freibergs zu verdeutlichen. Hierbei gilt es den Blick über das Lokale $^{10}$ hinaus $\mathrm{zu}$ weiten und das Ringen um die sächsische Bergstadt in einer Zusammenschau von lokaler, regionaler und mächtepolitischer Ebene zu kontextualisieren.

\section{Kursachsen und der europäische Krieg ab 1635}

Seit Mitte der 1630er-Jahre bildeten sich sukzessive die für den weiteren Kriegsverlauf dominierenden Blöcke aus, welche aus dem ,Teutschen Krieg' mit europäischer Beteiligung endgültig einen europäischen Konflikt machten, der hauptsächlich auf dem Boden des Alten Reiches ausgetragen wurde und erst durch einen allgemeinen Frieden beendet werden konnte. ${ }^{11}$ So verfestigte sich mit dem aktiven Eingreifen Frankreichs und Spaniens im Reich einerseits ein Lager mit den spanischen und österreichischen Habsburgern nebst den armierten Kurfürsten des Reiches, zu dessen Antipoden sich andererseits eine Interessengemeinschaft mit

Dresdner Hefte 56 (1998): Sachsen im Dreißigjährigen Krieg; Uwe Fiedler (Hg.), Der Kelch der bittersten Leiden. Chemnitz im Zeitalter Wallensteins und Gryphius, Chemnitz 2008.

9 Vgl. Axel GotThard, „Politice seint wir bäpstisch“. Kursachsen und der deutsche Protestantismus im frühen 17. Jahrhundert, in: Zeitschrift für historische Forschung 20 (1993), S. 275-319; Johannes Burkhardt, Friedensschlüsse auf Sächsisch. Pazifizierende Sprachleistungen eines deutschen Landesstaates in der ersten Hälfte der Frühen Neuzeit, in: Heinz Duchhardt/Martin Espenhorst (Hg.), Frieden übersetzen in der Vormoderne. Translationsleistungen in Diplomatie, Medien und Wissenschaft, Göttingen 2012, S. 36-65.

10 Mit diesem Fokus z. B. Heinrich Gerlach, Zur Feier der Erinnerung an die vor 250 Jahren erfolgte Befreiung Freibergs von der schwedischen Belagerung, in: Mitteilungen des Freiberger Altertumsvereins 28 (1891), S. 1-8; KonRad Knebel, Peter Schmohl. Königlich Schwedischer und Kurfürstlich Sächsischer Hauptmann, in: ebd. 38 (1902), S. 75-85; Kurt Bley, Aus Freibergs vergangenen Tagen. Ein Heimatbuch, Freiberg 1926, S. 78-86; Walter Schellhas, Vom Vorabend der frühbürgerlichen Revolution bis zum Ende des Dreißigjährigen Krieges. 1470-1648, in: Hanno-Heinz Kasper/Eberhardt Wächtler (Hg.), Geschichte der Stadt Freiberg, Weimar 1986, S. 91-142; GüNTER Oelschlegel, Die Schweden vor Freiberg. Erzählungen aus dem Dreißigährigen Krieg, Leipzig 1997.

11 Vgl. KonRad Repgen, Dreißigjähriger Krieg, in: Frank Bosbach/Konrad Repgen (Hg.), Dreißigjähriger Krieg und Westfälischer Friede (Rechts- und staatswissenschaftliche Veröffentlichungen der Görres-Gesellschaft N. F. 81), Paderborn u. a. 1998, S. 291-318, hier S. 310-314; Kleinehagenbrock, Das Alte Reich (wie Anm. 6), S. 135 f.; Kampmann, Europa und das Reich (wie Anm. 5), S. 128. 
Schweden, Frankreich und den Generalstaaten als den Hauptmächten herauskristallisierte. ${ }^{12}$ Hatte der sächsische Kurfürst Johann Georg I. (1585-1656) zunächst auf Seiten des habsburgischen Kaisers und ab Anfang der 1630er-Jahre im Verbund mit den Schweden gegen das Reichsoberhaupt gekämpft, distanzierte er sich infolge der nachhaltigen Erschütterung der schwedischen Vormachtstellung durch die Schlacht bei Nördlingen am 5./6. September 163413 endgültig vom eher ungeliebten Bündnis und näherte sich wieder der kaiserliche Seite an. ${ }^{14}$ Besiegelt wurde die Rückkehr des wohl bedeutendsten protestantischen Reichsstandes ins Lager der Kaiserlichen nach seinem schwedischen Intermezzo schließlich mit dem Prager Friedensschluss vom 30. Mai 1635, auf dessen Grundlage das Reich befriedet und die fremden Kronen auch mit militärischen Mitteln aus dem Reich gedrängt werden sollten, insofern sie sich nicht dem Frieden anschlössen. ${ }^{15}$ Jedoch war diesem Unternehmen kein durchschlagender Erfolg vergönnt. Denn zunächst scheiterten die Bemühungen des sächsischen Kurfürsten, auf der Grundlage des Prager Friedens zu einem Ausgleich mit den Schweden zu kommen. Dabei bediente sich der Wettiner als Befehlshaber des protestantischen Korps der neuen Reichsarmee

12 Vgl. Kampmann, Europa und das Reich (wie Anm. 5), S. 103-109; Burkhardt, Dreißigjähriger Krieg (wie Anm. 5), S. 42-50; Volker Ruhland, Der Dreißigjährige Krieg und Kursachsen, in: Sächsische Heimatblätter 40 (1994), S. 325-333, hier S. 326. - Ausführlich zur französischen Außenpolitik: Anuschka Tischer, Französische Diplomatie und Diplomaten auf dem Westfälischen Friedenskongreß. Außenpolitik unter Richelieu und Mazarin (Schriftenreihe der Vereinigung zur Erforschung der Neueren Geschichte 29), Münster 1999, S. 181-208; Anja Victorine Hartmann, Von Regensburg nach Hamburg. Die diplomatischen Beziehungen zwischen dem französischen König und dem Kaiser vom Regensburger Vertrag (13. Oktober 1630) bis zum Hamburger Präliminarfrieden (25. Dezember 1641) (Schriftenreihe der Vereinigung zur Erforschung der Neueren Geschichte 27), Münster 1998.

13 Ausführlich: Peter Engerisser/Pavel HrnčiŘík, Nördlingen 1634. Die Schlacht bei Nördlingen. Wendepunkt des Dreißigjährigen Krieges, Weißenstadt 2009.

14 Zur Kriegspolitik Kursachsens und Johann Georgs I. als Verfechter der Reichsidee vgl. Johannes Burkhardt, Der Dreißigjährige Krieg. Einfluß der sächsischen Politik auf die deutsche Geschichte, in: Dresdner Hefte 56 (1998), S. 3-12; Hendrik Thoss, Sachsen im Dreißigjährigen Krieg. Diplomatie und Politik, in: Fiedler, Kelch (wie Anm. 8), S. 21-29. Dagegen: Karlheinz Blaschke, Sachsen im Dreißigjährigen Krieg, in: Sächsische Heimatblätter 41 (1995), S. 229-233. Da eine ausführliche Biografie zur Person des Kurfürsten bisher noch ein Desiderat darstellt, siehe lediglich Axel GotTHARD, Johann Georg I. 1611-1656, in: Frank-Lothar Kroll (Hg.), Die Herrscher Sachsens. Markgrafen, Kurfürsten, Könige 1089-1918, München 22013, S. 137-147.

15 Vgl. Kathrin Bierther (Bearb.), Die Politik Maximilians von Bayern und seiner Verbündeten 1618-1651. Der Prager Frieden von 1635 (Briefe und Akten zur Geschichte des Dreißigjährigen Krieges N. F., Teil 2, Bd. 10), München/Wien 1997. Zum Vertragstext vgl. Frieden von Prag, Kaiser, Sachsen (Kurfürstentum), 30. Mai 1635, in: Heinz Duchhardt/Martin Espenhorst (Hg.), Europäische Friedensverträge der Vormoderne online, http://www.ieg-friedensvertraege.de [Zugriff 1. Juni 2015]. Der Vertrag griff mit seinen Regelungen denen auf dem Westfälischen Friedenskongress vor und eröffnete eine Basis für eine Friedensordnung im Reich. Vgl. Kampmann, Europa und das Reich (wie Anm. 5), S. 109-116; vertiefend: Ralf-Peter Fuchs, „Ein Medium zum Frieden“. Die Normaljahrsregel und die Beendigung des Dreißigjährigen Krieges (Bibliothek Altes Reich 4), München 2010. 
einer zweigleisigen Kriegführung, die sowohl aus einer diplomatischen wie aus einer militärischen Komponente bestand. ${ }^{16}$ Zunächst waren die Schweden auch auf Verhandlungen eingegangen. Doch nachdem im Sommer 1635 keine für beide Seiten akzeptable Einigung erzielt werden konnte und sich die militärische Lage der Schweden nach dem Waffenstillstand mit Polen und mit der Niederlage des kaiserlich-sächsischen Korps der Reichsarmee bei Wittstock an der Dosse ${ }^{17}$ bis zum Herbst 1636 wieder stabilisierte, sollten sie nun ihrerseits versuchen, im Schulterschluss mit den Franzosen auf einen Ausgleich zu ihren Bedingungen hinzuwirken. ${ }^{18}$ Dazu knüpften Schweden und Frankreich mit dem Vertrag von Wismar, dem Hamburger Vertrag vom März 1638 und dessen Verlängerung im Jahre 1641 bis zum Kriegsende ${ }^{19}$ ihre Allianz immer enger. Als Resultat dieser Entwicklungen entstanden im Lager um den neuen Kaiser Ferdinand III. noch stärkere Kohäsionsbemühungen. So wurde die Bindung Wiens an Madrid20 ebenso gestärkt wie versucht, wenigstens die Reihen der Reichsstände auf der Grundlage des Prager Friedens zu schließen, um so den ,Kampf um den besten Frieden' für sich zu entscheiden. ${ }^{21}$

16 Vgl. Heiner Haan, Kaiser Ferdinand II. und das Problem des Reichsabsolutismus. Die Prager Heeresreform von 1635, in: Hans Ulrich Rudolf (Hg.), Der Dreißigjährige Krieg. Perspektiven und Strukturen, Darmstadt 1977, S. 208-264; Fritz Dickmann, Der Westfälische Frieden, Münster 61972, S. 74-77; ERnst DürвecK, Kursachsen und die Durchführung des Prager Friedens 1635, Borna/Leipzig 1908, S. 75-85; Sigmund Goetze, Die Politik des schwedischen Reichskanzlers Axel Oxenstierna gegenüber Kaiser und Reich, Kiel 1971, S. 188-192.

17 Zum Schlachtverlauf: Sennewald, Kursächsisches Heer (wie Anm. 7), S. 269-294. Darüber hinausgehend zur Schlachtfeldarchäologie bei Wittstock: SABINE EICKHOFF u. a., 1636 - ihre letzte Schlacht. Leben im Dreißigjährigen Krieg, Stuttgart 2012.

18 Vgl. Öhman, Kampf um den Frieden (wie Anm. 6), S. 69-98; Schormann, Dreißigjähriger Krieg (wie Anm. 5), S. 55; GoETzE, Politik des schwedischen Reichskanzlers (wie Anm. 16), S. 188-200; Heiner Haan, Reichsabsolutismus (wie Anm. 16), S. 243. Die Bemühungen um einen gesonderten Ausgleich mit Schweden von 1635 bis 1640 aus sächsischer Sicht zusammengefasst in: Sächsisches Staatsarchiv - Hauptstaatsarchiv Dresden (im Folgenden: HStA Dresden), 10024 Geheimer Rat (Geheimes Archiv), Loc. 8112/2, fol. 92-101.

19 Unter der Maßgabe, keinen Sonderfrieden mit dem Kaiser abzuschließen, flossen hohe Subsidien in die schwedischen Kassen, was die Möglichkeiten zur offensiven Kriegsführung beförderte und auf die Erfüllung der eigenen Kriegsziele hoffen ließ. Vgl. Höfer, Ende des Dreißigjährigen Krieges (wie Anm. 6), S. 27; BurkhardT, Dreißigjähriger Krieg (wie Anm. 5), S. 15 f. - Kampmann sieht den Krieg mit dem Hamburger Vertrag in eine neue Qualität eintreten, indem er sich nun zu einem Ringen um die beste Ausgangssituation für Friedensverhandlungen wandelte. Vgl. Kampmann, Europa und das Reich (wie Anm. 5), S. 126; desgleichen ÖHman, Kampf um den Frieden (wie Anm. 6), S. 148-153. Zu den schwedischen Kriegszielen vgl. Sven Lundkvist, Die schwedischen Kriegs- und Friedensziele 1632-1648, in: Konrad Repgen (Hg.), Krieg und Politik 1618-1648. Europäische Probleme und Perspektiven, München 1988, S. 219-240.

20 Vgl. Schormann, Dreißigjähriger Krieg (wie Anm. 5), S. 67, 83; Kampmann, Europa und das Reich (wie Anm. 5), S. 133-138; Dickmann, Westfälischer Frieden (wie Anm. 16), S. 95, 103.

21 Vgl. Lothar Höвelt, Ferdinand III. (1608-1657). Friedenskaiser wider Willen, Graz 2008, S. 163-176. So wurde auf dem Reichstag 1640/41 ein Verbot von Sonderfriedens- 
Kursachsen hielt denn auch bis in die 1640er-Jahre weiter am Bündnis mit dem Kaiser und den Bestimmungen des Prager Friedens fest, auch wenn es sukzessive militärisch wie diplomatisch in die Defensive gedrängt wurde. Schon bei Wittstock hatte das kursächsische Heer einen Teil der militärischen Schlagkraft eingebüßt und musste reorganisiert werden. Der Verlust konnte jedoch in den Folgejahren nicht wieder vollständig kompensiert werden. Vielmehr war Kursachsen nach den abermals verlustreichen Feldzügen der ausgehenden 1630er- und beginnenden 1640er-Jahre immer mehr auf eine aktive militärische Unterstützung des Kaisers angewiesen. Die sächsische Infanterie beschränkte sich infolgedessen zunehmend auf die Verteidigung fester Plätze im Kurfürstentum, und die Masse der Kavallerie unterstützte die kaiserliche Hauptarmee. ${ }^{22}$

Parallel dazu wurde Kursachsen zu einem der Hauptkriegsschauplätze der schwedischen Armee, nachdem diese durch die Verträge mit Frankreich die Möglichkeit zurückerhielt, weitgreifende Offensiven zu führen. Die schwedische Armeeführung, zunächst unter Johan Banér (1596-1641), sah nach der Sicherung der Ostseeküste ihr weiteres Operationsziel in einem Vorstoß in Richtung der habsburgischen Erblande. Eine Verlagerung des Krieges in diese Gebiete zielte darauf $\mathrm{ab}$, dem Kaiser die materielle Basis zur Kriegsführung zu rauben. ${ }^{23}$ Gleichzeitig sollten die Vorstöße das bis dato militärisch noch überlegene kaiserliche Bündnis unterminieren, damit dessen Mitglieder sukzessive aus dem Verbund des Kaisers gelöst werden konnten. Nachdem Kurbrandenburg nach der Wittstocker Schlacht praktisch kaum noch ins aktive Kriegsgeschehen eingriff, ${ }^{24}$ zielten die schwedischen Feldzüge 1639 und 1640/41 neben dem Vorstoß in die habsburgischen Ländereien darauf ab, vor allem auch den sächsischen Kurfürsten, wenn

schlüssen der Reichsstände, die ohne Genehmigung des Kaisers erfolgten, in den Reichstagsabschied aufgenommen. Vgl. Neue und vollständige Sammlung der Reichsabschiede, Teil 3: Derer Reichs=Abschiede von dem Jahr 1552 bis 1654 inclusive, Frankfurt am Main 1747, S. 564; Dickmann, Westfälischer Frieden (wie Anm. 16), S. 99-103; Kampmann, Europa und das Reich (wie Anm. 5), S. 129-135.

22 Vgl. Sennewald, Kursächsisches Heer (wie Anm. 7), S. 513-518, 549-579. Das bayerische Korps führte hingegen noch einen recht erfolgreichen Krieg gegen die Franzosen. Vgl. Ruppert, Kaiserliche Politik (wie Anm. 6), S. 12 f.; Johann Heilmann, Die Feldzüge der Bayern in den Jahren 1643, 1644 und 1645 unter den Befehlen des Feldmarschalls Franz Freiherrn von Mercy, Leipzig/Meißen 1851.

23 Zum Umfang und zur wirtschaftlichen Bedeutung der Erblande für die habsburgischen Kaiser siehe: Ruppert, Kaiserliche Politik (wie Anm. 6), S. 10.

24 Der brandenburgische Kurfürst Georg Wilhelm setzte zwar die Aufstellung eines eigenen Heeres durch und wurde zum vierten General der Reichsarmada, überreizte dabei jedoch die Ressourcen Brandenburgs und schied aus dem praktischen Kriegsgeschehen aus. Vgl. Ernst Opgenoorth, Friedrich Wilhelm. Der große Kurfürst von Brandenburg. Eine politische Biographie, 1. Teil: 1620-1660, Göttingen/Frankfurt/ Zürich 1971, S. 76-88; HaAn, Reichsabsolutismus (wie Anm. 16), S. 254; Matthias Asche, Neusiedler im verheerten Land. Kriegsfolgenbewältigung, Migrationssteuerung und Konfessionspolitik im Zeichen des Landeswiederaufbaus. Die Mark Brandenburg nach den Kriegen des 17. Jahrhunderts, Münster 2006, S. 32-35. 
nicht in die Knie zu zwingen, so ihn wenigstens ernsthaft zu bedrohen und nachhaltig zu schwächen. ${ }^{25}$

\section{Sachsen und Freiberg als Ziel der schwedischen Armee}

Infolge dieser Entwicklungen wurde im Frühjahr 1639 auch das sächsische Freiberg zum Ziel der schwedischen Armee. ${ }^{26}$ Seine verkehrsgünstige Lage machte es zu einer idealen Drehscheibe für weitere Operationen beispielsweise in Richtung Böhmen oder gegen Leipzig beziehungsweise die kurfürstliche Residenz Dresden. Des Weiteren war Freiberg überregional als Stadt des Silberbergbaus bekannt, was materiell die Aussicht auf reiche Beute bedeutete. Zudem sollte der symbolische Wert der Stadt nicht unterschätzt werden, befand sich im Dom doch auch die Grablege der sächsischen Kurfürstenfamilie. ${ }^{27}$

Erstmals erschien die Armee der Schweden im März 1639 vor den Mauern ${ }^{28}$ und versuchte dabei rasch, an mehreren Toren in die Stadt einzudringen. Es gelang den Belagerern auch, eine Bresche in die Mauer zu schießen, doch der Widerstand der kurfürstlichen Garnison, der Bürgerschaft und der Freiberger Bergleute sowie der anrückende Entsatz durch kursächsisch-kaiserliche Truppen nötigten Banér gut zwei Wochen nach dem Beginn der Belagerung zum Abzug seiner Truppen in günstigeres Gelände. Bei Hohenstein in der Nähe von Chemnitz vermochte er es dann am 14. April 1639, das verbündete Heer aus Sachsen und Kaiserlichen zu schlagen. ${ }^{29}$ Trotz dieses Rückschlages wollten Ibro Churfürstliche Durchl. vom

25 Vgl. Parker, Dreißigjährige Krieg (wie Anm. 6), S. 247 f.

26 Schon im September 1632 waren die Stadt und die Region Schauplatz von Kriegshandlungen und einer kurzen Belagerung beim Einfall der Kaiserlichen geworden. Vgl. Andreas Möller, Theatrum Freibergense Chronicum. Beschreibung der alten löblichen BergHauptStadt Freyberg in Meissen, Ander Buch [...], Freiberg 1653, S. $470-$ 478; Hans-Jürgen ArendT, Wallensteins Faktotum. Der kaiserliche Feldmarschall Heinrich Holck (1599-1633), Ludwigsfelde 2004, S. 147. In der Folge hatte Freiberg unter Truppendurchzügen, Einquartierungen und Plünderungen zu leiden, aber die Schwedeneinfälle übertrafen diese vorhergehenden Ereignisse an Bedeutung. Vgl. Schellhas, Vorabend (wie Anm. 10), S. 116.

27 Vgl. Michael Hempel, Von dem Begräbnüß Des Hochlöblichen Chur und Fürstlichen Geschlechts / vnnd Stammes Sachssen / welches in der weitberühmbten / alten / löblichen Bergstadt Freybergk / in Meissen / in der Thumbkirchen / zu vnser lieben Frawn genannt [...], Freiberg 1605; Andreas Möller, Theatrum Freibergense Chronicum. Beschreibung der alten löblichen BergHauptStadt Freyberg in Meissen [...], Freiberg 1653, S. 61-96.

28 Die Hauptbefestigungsanlagen der Stadt waren seit ihrer Errichtung immer wieder verstärkt worden, stellten aber keineswegs den aktuellen Stand der Fortifikationstechnik dar. Zur Fortifikationstechnik vgl. GeOrg Ortenburg, Waffen der Landsknechte, Bonn 1984, S. 158-166. Eine zeitgenössische Beschreibung und ein Kupferstich der Freiberger Anlagen bei: Möller, Theatrum Freibergense Chronicum (wie Anm. 27), S. 26-36.

29 Vgl. Außführliche Relation vnd Bericht / Von der vnversehenen / gefährlichen vnd harten ploquada vnd Belagerung der Chrurfürstlichen Sächsichen eltesten BergkStadt 
Pragerischen Friedens $=S c h l u \beta$ so gar nicht weichen $/$ da $\beta$ sie eher alles auffsetzen $/$ alles zu Grund und Boden gehen lassen wolten / ehe daß sie wider gedachten Schluß etwas handeln sollten. ${ }^{30}$ Folgerichtig kehrten die Schweden wiederum vor Freibergs Mauern zurück und nahmen die Belagerung von Neuem auf, um den Druck auf Johann Georg I. nochmals zu steigern und ihn eventuell doch noch vom kaiserlichen Bündnis abzubringen. Als es auch die nun größere schwedische Armee nicht schaffte, die Verteidiger innerhalb weniger Tage zu überrennen, entschloss sich Banér, nicht noch weitere Zeit und Schlagkraft durch eine langwierige Belagerung Freibergs zu opfern, und konzentrierte sich nunmehr auf sein Hauptziel, den Vorstoß nach Böhmen. So brach die schwedische Armee am 25. April 1639 die Zelte vor dem von Banér angeblich nur ,Rattennest' genannten Freiberg $\mathrm{ab}$ und rückte in Richtung der böhmischen Grenze vor. ${ }^{31}$

Jedoch war weder dieser noch der Feldzug des folgenden Jahres von durchschlagendem Erfolg gekrönt, denn die Schweden waren nicht in der Lage, bis nach Österreich durchzustoßen oder sich im Königreich Böhmen beziehungsweise in Kursachsen nachhaltig festzusetzen. Dessen ungeachtet zeichnete sich dennoch immer mehr ab, dass die Schweden langsam die militärische Oberhand gewannen, da es die kaiserliche Seite nicht mehr vermochte, Krisen der schwedischen Armee wie nach dem plötzlichen Tod Banérs im Frühsommer 1641 durch eigene Offensiven auszunutzen. ${ }^{32}$ Diese Veränderung der militärischen Lage Anfang der 1640er-Jahre und die Krise der spanischen Habsburger ${ }^{33}$ waren dann auch ein wesentlicher Faktor dafür, dass sich die kaiserliche Seite nun darauf einließ, über die Abhaltung eines allgemeinen Friedenskongresses zu verhandeln. Mit den Hamburger Präliminarien wurden schließlich auch die ersten Rahmenbedingungen für einen allgemeinen Friedenskongress an zwei konfessionell getrennten Verhandlungsorten festgelegt. Was bis zur Eröffnung der eigentlichen Verhandlungen folgte, war das militärische Ringen um die Vormacht auf den Schlachtfel-

Freybergk in Meissen / Wie dieselbe am 2. Martij / dieses 1639. Jahres durch die Schwedischen Panierischen Völcker umb den Mittag in einem grossen Nebel ist angefangen [...], Freiberg 1639; SEnnewald, Kursächsisches Heer (wie Anm. 7), S. 331341.

30 Heinrich Oraeus, Theatrum Europaeum, Teil 4: Das ist: Glaubwürdige Beschreibung Denckwürdiger Geschichten [...] im KriegsWesen seithero Anno 1638. biß Anno 1643. exclusive begeben haben, Frankfurt am Main 1648, S. 97.

$31 \mathrm{Vgl}$. Continuation der Schwedischen Panierischen beschriebenen Belagerung der Stadt Freybergk Anno 1639 [...], o. O. 1643.

32 Vgl. Kleinehagenbrock, Das alte Reich (wie Anm. 6), S. 139; Kampmann, Europa und das Reich (wie Anm. 5), S. 131; PArker, Dreißig)ähriger Krieg (wie Anm. 6), S. 253; Ruppert, Kaiserliche Politik (wie Anm. 6), S. 15.

33 Zusammengefasst zur Krise der spanischen Monarchie: Michael Rohrschneider, Der gescheiterte Frieden von Münster. Spaniens Ringen mit Frankreich auf dem Westfälischen Friedenskongress (1643-1649) (Schriftenreihe der Vereinigung zur Erforschung der Neueren Geschichte 30), Münster 2007, S. 34 f.; KampmanN, Europa und das Reich (wie Anm. 5), S. 139-142. Zur Bedeutung der spanischen Unterstützung für die kaiserliche Kriegsführung vgl. Hildegard ERnst, Spanische Subsidien für den Kaiser 1632-1642, in: Repgen, Krieg und Politik (wie Anm. 19), S. 299-302. 
dern, welche dann in Vorteile auf diplomatischer Ebene bei den Unterredungen umgesetzt werden konnte. ${ }^{34}$ In diesem Kontext sind nun die Feldzüge Lennart Torstenssons, dem Nachfolger Banérs, und die Belagerung Freibergs zu sehen.

\section{Der Feldzug Torstenssons 1642 - der Vorlauf zur Belagerung Freibergs}

Nachdem der neue brandenburgische Kurfürst Friedrich Wilhelm (1620-1688) sich im Juni 1641 mit Schweden über eine vertragliche Neutralität ${ }^{35}$ seines Territoriums verständigt hatte, war faktisch das eingetreten, was mit dem Reichstagsabschied von 1641 eigentlich verhindert werden sollte, die Verständigung einzelner Reichsstände mit den fremden Kronen in Separatverhandlungen. Mit der Neutralität Brandenburgs hatten es die Schweden erfolgreich bewerkstelligt, einen wesentlichen Protagonisten aus der kaiserlichen Phalanx herauszubrechen. Damit war ein prominenter Präzedenzfall geschaffen worden, auf dessen Grundlage nun im Zusammenspiel von militärischem Druck und diplomatischen Vorstößen das kaiserliche Bündnis weiter demontiert werden sollte. ${ }^{36}$

Genau diese Strategie lag auch dem Handeln Lennart Torstenssons zugrunde. Zunächst musste er nach dem Tod Banérs die in Aufruhr geratenen Truppen zur Disziplin rufen. Danach sollte er den Krieg zuerst nach Mitteldeutschland, anschließend ins Meißner Land und letztendlich bis ins Königreich Böhmen verlagern, um das Kriegsglück nachhaltig zu Gunsten Schwedens zu wenden. Dabei war der Kurfürst von Sachsen wie ein Feind zu behandeln, um ihn ebenfalls vom kaiserlichen Bündnis zu lösen. Mittelfristig waren die Schweden aber bestrebt, wieder zu einem Ausgleich mit Johann Georg I. zu kommen. ${ }^{37}$

34 Vgl. Dickmann, Westfälischer Frieden (wie Anm. 16), S. 104 f.; Kampmann, Europa und das Reich (wie Anm. 5), S. 131 f.; Kleinehagenbrock, Das alte Reich (wie Anm. 6), S. 138 f.; Konrad Repgen, Die Westfälischen Friedensverhandlungen. Überblick und Hauptprobleme, in: Klaus Bußmann (Hg.), 1648 - Krieg und Frieden in Europa, Bd. 1: Politik, Religion, Recht und Gesellschaft, Münster 1998, S. 355-372, hier S. 355357.

35 Der Neutralitätsbegriff wurde erst mit dem Naturrecht in seinem Umfang genauer definiert. Im 17. Jahrhundert wurde er jedoch mehrheitlich mit Untreue und Sündhaftigkeit gleichgestellt und somit allgemein negativ konnotiert. Vgl. Axel GotTHARd, Neutralität, in: Friedrich Jaeger (Hg.), Enzyklopädie der Neuzeit, Bd. 9: NaturhaushaltPhysiokratie, Stuttgart/Weimar 2009, Sp. 152-157, hier Sp. 154 f.; zum Brandenburger Neutralitätsvertrag: Opgenoorth, Friedrich Wilhelm (wie Anm. 24), S. 89-102; Theodor von Moerner (Bearb.), Kurbrandenburgs Staatsverträge von 1601 bis 1700. Nach den Originalen des Königlich Geheimen Staatsarchivs, Berlin 1867, S. 129-131.

36 Vgl. Höfer, Ende des Dreißigjährigen Krieges (wie Anm. 6), S. 29; Dickmann, Westfälischer Frieden (wie Anm. 16), S. 109; PARKer, Dreißigjähriger Krieg (wie Anm. 6), S. 253 f.; Schmidt, Dreißigjähriger Krieg (wie Anm. 5), S. 66 f.; Günter Barudio, Der Teutsche Krieg 1618-1648, München 1998.

37 Vgl. Inger Schuberth, Die Rolle Schwedens im Dreißigjährigen Krieg, in Sächsische Heimatblätter 41 (1995), S. 333-337, hier S. 337; PARker, Dreißigjähriger Krieg (wie Anm. 6), S. 245 f. 
Nachdem Torstensson die Unruhen in seiner Armee befriedet hatte, setzte er seine Einheiten umgehend in Richtung der habsburgischen Erblande in Bewegung. ${ }^{38}$ Durch die Neutralität Kurbrandenburgs lagen Schlesien und Kursachsen praktisch offen vor ihm. Er wählte zum Auftakt des Feldzuges von 1642 zunächst eine östliche Route über Schlesien. Dabei führte die schwedische Armee einen erfolgreichen Festungskrieg und schlug am 31. Mai 1642 bei Schweidnitz (Świdnica) die kaiserlich-sächsischen Truppen des Herzogs Franz Albert von Sachsen-Lauenburg. Damit war der Weg nach Mähren freigekämpft, wo im Juni 1642 auch die beherrschende Festung Olmütz (Olomuc) in die Hände der Schweden fiel. Danach waren die schwedischen Kräfte vorerst erschöpft, weshalb die Armee ihren Vormarsch abbrach und sich nach Sachsen wandte. ${ }^{39}$ Einerseits beabsichtigte Torstensson sich hier mit Verstärkungen zu vereinigen beziehungsweise die Armee zu versorgen, andererseits sollte das Verlagern des Krieges in das Kurfürstentum den Druck auf Johann Georg I. erhöhen.

Auf ihrem Weg eroberten die schwedischen Truppen schließlich Zittau, um im Anschluss durch Nordsachsen in Richtung Leipzig vorzudringen und schließlich die Messestadt zu belagern. ${ }^{40}$ Torstenssons Kalkül dabei war, entweder sich durch die Eroberung der Stadt deren Einnahmen und ein gutes Winterquartier zu sichern oder die verfolgende kaiserliche Hauptarmee zu einem Entsatzversuch zu zwingen, um sie in eine offene Feldschlacht zu locken und bestenfalls zu besiegen. Der Oberkommandierende der kaiserlichen Truppen und Bruder Ferdinands III., Erzherzog Leopold Wilhelm (1614-1662), entschied sich letztendlich für einen Angriff auf die zahlenmäßig schwächeren Schweden, jedoch unterlag die kaiserliche Armee am 2. November 1642 in unmittelbarer Nachbarschaft des Kampfplatzes von 1631 dem ,Lehrling' Gustav Adolfs. Die kaiserlichen Truppen flüchteten teilweise vom Schlachtfeld, wurden versprengt und zogen sich in Richtung Böhmen zurück. ${ }^{41}$ Nach dem Sieg in der Schlacht wandten sich die Schweden abermals gegen Leipzig. Jetzt ohne Aussicht auf Entsatz schlossen am 5. Dezember 1642 zunächst der Kommandant der Pleißenburg und am folgenden Tag auch der Stadtkommandant eine Übereinkunft mit dem schwedischen Feldmarschall,

38 Analog zu Banér verfolgte auch Torstensson diese Strategie. Vgl. Kampmann, Europa und das Reich (wie Anm. 5), S. 143; Ruppert, Kaiserliche Politik (wie Anm. 6), S. 15; Öhman, Kampf um den Frieden (wie Anm. 6), S. 162 f.

$39 \mathrm{Vgl}$. Peter Englund, Verwüstung. Eine Geschichte des Dreißigjährigen Krieges, Reinbek bei Hamburg 2013, S. 325-330; Robert Rebitsch, Matthias Gallas (15881647). Generalleutnant des Kaisers zur Zeit des Dreißigjährigen Krieges. Eine militärische Biographie, Münster 2006, S. 229; Oraeus, Theatrum Europaeum 4 (wie Anm. 30), S. 888-893.

40 Vgl. Gründliche und Eigentliche Relation, Von der harten und strengen Belagerung der vornehmen Kauff- Handels Stadt Leipzig und Vestung Bleißenburg [...], o. O. 1643.

41 Vgl. Gründlicher und eigentlichter Bericht. Wie es bey der / den 23. Octobr. 2. Nov. Anno 1642. nicht weit von Leipzig zwischen den Keyserlichen und Schwedischen gehaltener blutigen Schlacht und Treffen eigentlich hergegangen [...], o. O. 1642; Oraeus, Theatrum Europaeum 4 (wie Anm. 30), S. 901-903; PARker, Dreißigjähriger Krieg (wie Anm. 6), S. 255. 
infolgedessen die kurfürstlichen Soldaten einen ehrenvollen Abzug in Richtung Dresden erhielten. ${ }^{42}$

Mit dem Auszug der kursächsischen Garnison am 7. Dezember 1642 hatte Torstensson zwei wichtige Ziele erreicht: Er hatte einerseits einen sicheren Eckpfeiler für weitere Operationen gewonnen und Johann Georg I. mit dem Verlust der wichtigen Handelsstadt einen heftigen Schlag versetzt. Andererseits war die kaiserliche Hauptarmee derart versprengt worden, dass sie nun mit Sicherheit einige Zeit zu ihrer Reorganisation benötigen würde. Dementsprechend war die schwedische Seite nun versucht, diese Vorteile in Verhandlungsmacht gegenüber dem sächsischen Kurfürsten umzusetzen.

Schon vor dem Fall Leipzigs hatte angesichts des Siegeszugs der Schweden und der augenfälligen militärischen Schwäche Sachsens der Kurprinz Johann Georg (1613-1680) beim schwedischen Oberkommandierenden ausloten lassen, inwieweit Möglichkeiten zur Verhütung noch schlimmerer Zerstörungen in Kursachsen bestünden. ${ }^{43}$ Torstensson gab daraufhin zu erkennen, dass er nicht abgeneigt sei, in Sonderverhandlungen mit Kursachsen einzuwilligen und seine Truppen sofort von dessen Gebiet abzuziehen, sobald den Schweden ein fester Platz im Kurfürstentum, angemessene Kontributionen und freies Durchzugsrecht eingeräumt würden. Gleichzeitig drohte der Feldmarschall, mit einer Besetzung Großenhains oder Freibergs und mit der Errichtung von Musterplätzen den Kurfürsten noch fester zu umklammern. Jedoch war der Kurfürst auf dieses noch recht großzügige Angebot nicht eingegangen. ${ }^{44}$ Doch die Einnahme Leipzigs ließen die Aufforderungen des Kurprinzen an seinen Vater nochmals eindringlicher werden, mit der schnellen Entsendung eines Kuriers an den Feldmarschall weitere Schäden im Lande zu verhindern und zu eruieren, auf welcher inhaltlichen Grundlage ${ }^{45}$ Torstensson nun zu Verhandlungen bereit sein würde, da eine zeitnahe Konsolidierung der bei Breitenfeld versprengten kaiserlichen Armee mehr als fraglich und die militärische Überlegenheit der Schweden eklatant sei. ${ }^{46}$

42 Vgl. Gründliche und Eigentliche Relation (wie Anm. 40); Oraeus, Theatrum Europaeum 4 (wie Anm. 30), S. 905-911. Mit dem Abzug begann für Leipzig die Zeit der schwedischen Besetzung, die bis 1650 dauern sollte; dazu: Alexander ZIRR, Die Stadt Leipzig in der zweiten Hälfte des Dreißigjährigen Krieges, in: Ulrich von Hehl (Hg.), Stadt und Krieg. Leipzig in militärischen Konflikten vom Mittelalter bis ins 20. Jahrhundert (Quellen und Forschungen zur Geschichte der Stadt Leipzig 8), Leipzig 2014, S. 99-119.

43 Vgl. HStA Dresden, 10024 Geheimer Rat (Geheimes Archiv), Loc. 9260/3, fol. 1-4; Bogislaff Philip von Chemnitz, Königlichen Schwedischen in Teutschland geführter Krieg, 4. Teil [...], 2. Buch, N. D. Stockholm 1856, S. 146.

44 Vgl. HStA Dresden, 10024 Geheimer Rat (Geheimes Archiv), Loc. 9260/3, fol. 3; Loc. $8127 / 2$, fol. 2 .

45 Dabei galt als rote Linie der sächsischen Seite, dass der Kurfürst keinerlei Regelungen akzeptieren werde, die seine Pflichten gegen Kaiser und Reich verletzten. Eine Neutralität, wie sie noch Kurbrandenburg abgeschlossen hatte, war für Johann Georg I. ein Tabu und deren eventuelle Einforderung ein Grund, Verhandlungen auszuschlagen. Vgl. HStA Dresden, 10024 Geheimer Rat (Geheimes Archiv), Loc. 8127/2, fol. 7 f.

46 Vgl. HStA Dresden, 10024 Geheimer Rat (Geheimes Archiv), Loc. 8127/2, fol. 3. 
Während mindestens die beiden ältesten Söhne des Kurfürsten, Kurprinz Johann Georg und der Magdeburger Administrator August (1614-1680), ${ }^{47}$ Unterredungen mit dem Schweden positiv gegenüberstanden, sahen Teile des Geheimen Rates diese skeptisch. Hier wurde der Zusammenhang der Verhandlungsangebote mit der bevorstehenden Eröffnung des allgemeinen Friedenskongresses in Münster und Osnabrück hergestellt, für die der Feldmarschall den Schweden durch eine vertragliche Einigung mit Kursachsen eine noch bessere Position verschaffen wolle. Auch wischten sie die Berufung Torstenssons auf das gemeinsame lutherische Bekenntnis damit beiseite, dass er nur aus Machtinteresse und ohne gesonderte Rücksicht auf die Glaubensbrüder handele. ${ }^{48}$

Johann Georg I. willigte dennoch in die Bitte seines Sohnes ein. Dadurch konnte ein sächsischer Abgesandter mit dem Feldmarschall konferieren. Doch auch diesmal lehnte Johann Georg I. die schwedischen Angebote ab, auch nachdem er aufgezeigt bekommen hatte, dass nach dem Verlust Leipzigs und bei einem weiteren Abwarten im alleinigen Vertrauen auf das militärische Bündnis mit den indisponierten Kaiserlichen eine weitläufige Verwüstung des Landes, der Verlust weiterer wichtiger Orte und ihm eine Isolierung in seiner Residenz drohe. ${ }^{49} \mathrm{Wie}$ zutreffend diese Lageeinschätzung sein sollte, zeigte sich schon einige Tage später, als Torstensson nach dem Eintreffen der abschlägigen Antwort des Kurfürsten ${ }^{50}$ sowie der Eroberung von Chemnitz keine weiteren Verhandlungsangebote mehr unterbreitete, sondern sein Heer in Richtung Freiberg befahl.

\section{Die Belagerung Freibergs}

Nachdem die Schweden Freiberg vorerst nicht direkt behelligt und sich Leipzig zugewendet hatten, verdichteten sich spätestens nach der zweiten Breitenfelder

47 August versuchte sich seinerseits als Administrator Magdeburgs ebenfalls mit Torstensson zu einigen. Vgl. Inger SchuberTh, Brennpunkt Halle. Die Schweden kommen und gehen, in: Boje E. Hans Schmuhl/Thomas Bauer-Friedrich (Hg.), Im Land der Palme. August von Sachsen 1614-1680. Erzbischof von Magdeburg und Fürst in Halle, Halle an der Saale 2014, S. 81-91, hier S. 90.

48 Vgl. HStA Dresden, 10024 Geheimer Rat (Geheimes Archiv), Loc. 8127/2, fol. 9-11.

49 Vgl. ebd., fol. 19-34; Chemnitz, Krieg 4/2 (wie Anm. 43), S. 149-151.

50 Dabei hatte der Kurprinz den Feldmarschall darauf verwiesen, dass sobald sich die Gegebenheiten änderten, er diesen Verhandlungsfaden wieder aufnehmen würde. Vgl. Chemnitz, Krieg 4/2 (wie Anm. 43), S. 151. Die Unterredungen des Spätjahres 1642 waren also nicht über die Phase von Vorverhandlungen über die inhaltlichen Grundlagen zur Aufnahme von Verhandlungen hinausgekommen. Vgl. Franz Bosbach, Verfahrensordnungen und Verhandlungsabläufe auf den Friedenskongressen des 17. Jahrhunderts. Überlegungen zu einer vergleichenden Untersuchung der äußeren Formen frühneuzeitlicher Friedensverhandlungen, in: Christoph Kampmann u. a. (Hg.), L'art de la paix. Kongresswesen und Friedensstiftungen im Zeitalter des Westfälischen Friedens (Schriftenreihe der Vereinigung zur Erforschung der Neueren Geschichte 34), Münster 2011, S. 93-118, hier S. 107-109. 
Schlacht die Anzeichen für eine akute Bedrohung der sächsischen Bergstadt. ${ }^{51}$ Hatte der Landesherr zunächst aufgrund der unklaren Lage noch davon abgesehen, eine Garnison in Freiberg einzuquartieren, reagierte er schließlich parallel zu den diplomatischen Sondierungen im Rahmen seiner Möglichkeiten auch militärisch auf die Erfolge der Schweden. Nach dem Verlust des sächsischen Handelszentrums sollte nun nicht noch die Berghauptstadt mit ihren Einnahmen aus dem Silberbergbau und ihrer für Dresden so wichtigen strategischen Vorpostenlage verloren gehen. Deshalb ernannte der Kurfürst mit dem Obristenleutnant Georg Hermann von Schweinitz (1602-1667)52 einen erfahrenen Soldaten zum Kommandanten der Stadt Freiberg und befahl ihm, die Stadt bis zum Äußersten zu verteidigen. Dazu wurden von Schweinitz insgesamt 290 Mann geworbener kurfürstlicher Soldaten zur Verfügung gestellt, deren Ankunft nebst etlichen Munitionswagen in den Freiberger Stadtprotokollen für den 15. Dezember 1642 verzeichnet wurde. ${ }^{53}$ Neben diesen regulären Soldtruppen und den ansässigen Angehörigen des sächsischen Defensionswerkes ${ }^{54}$ bildeten die Bergleute ${ }^{55}$ der Region die dritte Säule der Verteidiger. Zu diesen drei Gruppen von Verteidigern sollte wie 1639 die Bürgerschaft unter dem Befehl der Bürgermeister treten. ${ }^{56}$ Diese Verteidiger sahen sich nach dem Jahreswechsel nun dem Gros der schwedi-

51 Nicht zuletzt zog auch Kurfürst Johann Georg I. selbst in Betracht, dass die Schweden ihr Augenmerk auf Freiberg richten würden. Vgl. StadtA Freiberg, Rep. AA, Abt. IX, Sek. I, 171, unpaginiert, Schreiben Johann Georgs I. an den Rat Freibergs vom 8. November 1642 [julian.].

52 Vgl. Heinrich Gerlach, George Herrmann von Schweinitz, in: Mitteilungen des Freiberger Altertumsvereins 3 (1862-1864), S. 205-216.

53 Vgl. StadtA Freiberg, Abt. I, Ba 9b, Stadt-Protocolle 1640-1645, S. 286.

54 Zur Entstehung, Gliederung und Verwendung des sächsischen Defensionswerkes: Rolf Naumann, Das kursächsische Defensionswerk (1613-1709), Leipzig 1916. Allgemein zur Bedeutung der Landesdefension im Reich: Winfried Schulze, Die deutschen Landesdefensionen im 16. und 17. Jahrhundert, in: Johannes Kunisch (Hg.), Staatsverfassung und Heeresverfassung in der europäischen Geschichte der frühen Neuzeit, Berlin 1986, S. 129-149.

55 Vgl. Walter Schellhas, Die Rolle der Bergleute bei der Verteidigung der Stadt Freiberg gegen die Schweden in den Jahren 1639 und 1642/43. Ein Beitrag zur Geschichte der Freiberger Bergarbeiterbewegung, in: Sächsische Heimatblätter 17 (1971), S. 162-170, hier S. 165.

56 Die genaue Anzahl der Verteidiger lässt sich nicht mehr mit völliger Sicherheit rekonstruieren, hier differieren die Quellen in ihren Aussagen. Das Theatrum Europaeum nennt die Zahl von 1200 kursächsischen Musketieren und Reitern mit Jüngern und Bergknappen. Vgl. Oraeus, Theatrum Europaeum 4 (wie Anm. 30), S. 916. Der Freiberger Chronist Andreas Möller bringt hingegen nur die 290 Mann geworbener Truppen in Anschlag. Vgl. Möller, Theatrum Freibergense, Ander Buch (wie Anm. 26), S. 591. Ein Brief aus Freiberg, den ein Bergmann während der Belagerung aus der Stadt zum Kurfürstenhof nach Dresden brachte, beziffert schließlich die Gesamtzahl aller wehrfähigen Männer in der Stadt auf bis zu 7 000. Vgl. HStA Dresden, 10024 Geheimer Rat (Geheimes Archiv), Loc. 9260/18, fol. 17. 
schen Hauptarmee ausgesetzt, die zu diesem Zeitpunkt etwa noch 5000 bis 6000 Mann Fußtruppen, einige Tausend Reiter und über 100 Geschütze umfasste. ${ }^{57}$

Als zunächst noch die Option im Raum stand, dass die Truppen Torstenssons nach der Einnahme von Chemnitz von dort aus in die Oberpfalz marschieren würden, um hier einen nächsten Vorstoß anzusetzen oder sich mit den französischen Truppen zu vereinigen, wurde mit dem Versuch einer schwedischen Vorhut am 5. Januar 1643, Freiberg handstreichartig zu nehmen, deren Intension klarer ersichtlich, ihre Aktionen zunächst auf Johann Georgs Kurfürstentum zu konzentrieren. ${ }^{58}$ Denn nachdem der erste Überfall von der kursächsischen Besatzung vereitelt worden war, zogen an den nächsten Tagen weitere berittene Einheiten auf, welchen acht Infanteriebrigaden und die Artillerie mit über 100 Geschützen und fünf Mörsern folgten. ${ }^{59}$

Was sich nun anschloss, war ein anderthalb Monate andauernder beständiger Wechsel aus militärischem Druck auf und Übergabeangeboten an die kursächsischen Verteidiger, wobei die schwedischen Belagerer die Intensität allmählich steigerten. Gleichzeitig rang man im kaiserlichen Lager darum, wie in dieser Situation gehandelt werden sollte. Der Kampf um Freiberg fand somit auf zwei Ebenen statt. 60

Der erste Akt der Belagerung begann mit dem Aufzug der schwedischen Armee und der Erkundigung Torstenssons nach der Person des Kommandanten und nach dessen Absichten, das heißt, ob dieser die Stadt überhaupt verteidigen wolle. Da von Schweinitz dies seinem Auftrag gemäß bejahte, beließ es der Feldmarschall bei einigen Schüssen auf das Peterstor, und seine Truppen verlegten sich in den folgenden Tagen trotz der winterlichen Wetterverhältnisse auf den Bau von Geschütz- und Mörserstellungen. Innerhalb weniger Tage hatten die Belagerer

57 Vgl. Oraeus, Theatrum Europaeum 4 (wie Anm. 30), S. 916; Oskar Schuster/ Friedrich August Francke, Die Geschichte der Sächsischen Armee von der Errichtung bis auf die neueste Zeit, 1. Teil, Leipzig 1885, S. 76.

58 Zuvor hatte sich Kurfürst Johann Georg I. an Leopold Wilhelm gewandt, um von diesem Hilfe bei einer Bedrohung Freibergs zu erhalten, wurde aber von diesem wegen der noch unklaren Lage vertröstet. Vgl. HStA Dresden, Geheimer Rat (Geheimes Archiv), Loc. 9260/18, fol. 8. Zum Krieg in der Oberpfalz: Martin Fieger, Die kriegerischen Ereignisse in der Oberpfalz vom Einfalle Banérs 1641 bis zum Westfälischen Frieden, Teil 1: Bis zur Belagerung Freibergs, Dillingen 1910, S. 47-51.

Vgl. Möller, Theatrum Freibergense, Ander Buch (wie Anm. 26), S. 592-596.

60 Dabei entspann sich ein intensiver Schriftverkehr zwischen dem Dresdner Kurfürstenhof, den Verteidigern Freibergs und der kaiserlichen Armeeführung in Nordböhmen beziehungsweise in Wien, der hier skizzenhaft auf der Grundlage der Überlieferungen im Hauptstaatsarchiv Dresden, im Freiberger Stadtarchiv und edierten Quellen aus dem Umfeld der kaiserlichen Armeeführung rekonstruiert werden soll. Vgl. HStA Dresden, Geheimer Rat (Geheimes Archiv), Loc. 9260/18; StadtA Freiberg, Rep. AA, Abt. IX, Sekt. I, 171; PAul KNAUTH, Aktenstücke zur Geschichte der dritten Schwedenbelagerung der Stadt Freiberg, in: Mitteilungen des Freiberger Altertumsvereins 35 (1898), S. 35-44; Bohumil BaD'ura u. a. (Hg.), Der große Kampf um die Vormacht in Europa, die Rolle Schwedens und Frankreichs. Quellen zur Geschichte des 30jährigen Krieges 1635-1643 (Documenta Bohemica bellum tricennale illustrantia 6), Prag 1978. 
schon 20 Geschütze gegen die Stadt in Stellung gebracht, und am Morgen des 11. Januars 1643 wurden daraus einige Schüsse abgegeben. Anschließend schickte der Feldmarschall abermals einen Unterhändler an die Stadtmauer, der dem Kommandanten kundtat, dass der Feldmarschall, nachdem er nun seine Armee vorgeführt und zum neuen Jabr61 hätte schießen lassen, Schonung im Falle einer Übergabe anbieten würde. Von Schweinitz ließ dessen ungeachtet mit Verweis auf die kurfürstlichen Befehle erneut abschlägig antworten. ${ }^{62}$

Infolgedessen kam es nun zu einigen ernsthaften Angriffsbemühungen der Schweden. Nachdem am ersten Tag die schon zum Sturm bereitstehende Infanterie aufgrund des fehlenden Erfolgs beim Brescheschießen wieder abmarschierte, folgten am 13. Januar zwei weitere Angriffe auf die Stadt, die jeweils durch die erfolgreiche Detonation von Minen eingeleitet wurden. Zunächst stürmten am Morgen etwa 150 Schweden gegen die Bresche vor. Sie wurden aber nach kurzer Zeit von den Verteidigern blutig abgewiesen. Das daraufhin unterbreitete Übergabeangebot Torstenssons lehnte von Schweinitz ab, auch wenn der Feldmarschall argumentierte, der Kommandant habe jetzt seiner Ehre Genüge getan und einen Sturm ausgehalten. Nun könne er die Stadt übergeben, denn das unbastionierte Freiberg könne dem Bezwinger von Festungen wie Großglogau und Leipzig wohl kaum weiteren Widerstand leisten. Dennoch konnten die Verteidiger auch einen weiteren wuchtigen Angriff zweier Brigaden erfolgreich zurückdrängen. ${ }^{63}$

Mit der Abwehr der beiden Sturmangriffe war der erste ernsthafte Versuch der Schweden fehlgeschlagen, die Stadt zu besetzen. Zwar hatten sie den Verteidigungsanlagen stark zugesetzt, aber ihnen war es nicht gelungen, in die Stadt vorzudringen. Dieser Erfolg trug wesentlich zur Hebung des Selbstvertrauens in der Stadt bei, denn es war deutlich geworden, dass man in der Lage war, auch einen energischen Angriff der Schweden parieren zu können. Deshalb entschlossen sich der Stadtrat und die Militärs am 14. Januar 1643, auch weiterhin auf keines der Übergabeangebote einzugehen. ${ }^{64}$

Nach diesem zweiten Akt der Belagerung kehrte eine gewisse Ruhe bei den Kampfhandlungen ein. Die Angreifer bereiteten sich nun auf eine förmliche Belagerung mit dem planmäßigen Vordringen in die Stadt vor. $\mathrm{Zu}$ diesem $\mathrm{Zweck}$ wurden zunächst idealtypisch die Annäherungsgräben erweitert, bestehende Geschützbatterien gesichert, weitere Minengänge gegen die Verteidigungswerke

61 Aufgrund der Differenz zwischen dem heute gebräuchlichen gregorianischen und dem zeitgenössisch von Schweden und Kursachsen genutzten julianischen Kalender erklärt sich, dass Torstensson den Beschuss vom 11. Januar 1643 als Neujahrsschießen titulierte.

62 Vgl. Möller, Theatrum Freibergense, Ander Buch (wie Anm. 26), S. 596 f.

63 Vgl. HStA Dresden, Geheimer Rat (Geheimes Archiv), Loc. 9260/18, fol. 1-5, 9, 17; Gründliche und eigentliche Relation, von der Belagerung der Stadt Freyberg, in: Freybergische Stadt=Jubel=Acta (wie Anm. 4), S. 99 f.

64 Vgl. StadtA Freiberg, Abt. I, Ba, 9b, Stadt-Protocolle 1640-1645, S. 289 f. 
vorangetrieben und aus Leipzig und Erfurt Munition herbeigeschafft. ${ }^{65}$ Aufgrund der Verzögerungen bei der Einnahme Freibergs wurde von schwedischer Seite ein temporärer Vorstoß der Kavallerie in Richtung Böhmen angedacht, um einen eventuellen Entsatz durch kaiserliche Truppen schon im Aufbau zu stören, während die Infanterie den Ring um Freiberg weiter geschlossen hielt. Jedoch wurde das Unternehmen nach kurzer Zeit wieder abgebrochen, und man konzentrierte sich wieder auf die Belagerung der Stadt, ohne jedoch einen erneuten Sturm zu wagen. 66

Währenddessen versuchten die Verteidiger ihrerseits, die Bemühungen der Angreifer zu stören und durch begrenzte Ausfälle die Annäherung der Schweden $\mathrm{zu}$ hemmen sowie durch eingebrachte Gefangene Informationen zur Lage im Belagerungsheer zu beschaffen. ${ }^{67}$ So erfuhren die Verteidiger beispielsweise von dem ausbleibenden Erfolg der schwedischen Mineure, deren Arbeit immer wieder durch geschicktes Gegenarbeiten der Freiberger Bergleute vereitelt wurde. ${ }^{68}$ Die nasse und kalte Witterung ließ die Arbeit der schwedischen Knechte in den Laufgräben zur Tortur werden. Ende des Monats hatten die Schweden schon an die 2000 Mann Verluste an Toten, Verwundeten und Deserteuren, darunter viel wegen bösen Wetters erfroren, und hingestorben, derowegen die Soldatesca vber dem stäten Wachen, auch nothlayden an Proviandt vnnd Fourage, sebr unwillig gewesen seyn. ${ }^{69}$

Trotz aller bisher geglückten Versuche, die Versorgung in der Stadt aufrechtzuerhalten, ${ }^{70}$ war es den Verteidigern bewusst, dass man anhaltenden massiven Angriffen der Schweden nur sehr schwer würde widerstehen können. Aus diesem Grund hielten sie engen Kontakt zum Kurfürstenhof in Dresden sowie zum Kommando der kaiserlichen Armee. Die Bergleute der Stadt fungierten dabei als Boten, indem sie die Nachrichten durch die Bergwerksschächte unter dem schwedischen Belagerungsring hindurch brachten. ${ }^{71}$ Nur waren die Schreiben, welche man von

65 Vgl. Zeitungen Daß die Schwedischen von Freyberg nach dem sie die 2. Stürme verlohren und viel Volck eingebüsset [...], o. O. 1643; HStA Dresden, 10024 Geheimer Rat (Geheimes Archiv), Loc. 9260/18, fol. 12, 24.

66 Vgl. Bernhard Gentsch, Der Dreißigjährige Krieg und die ländlichen Untertanen im Erzgebirge und Vogtland, in: Jahrbuch für Regionalgeschichte 9 (1982), S. 207-234, hier S. 233; Müller, Theatrum Freibergense, Ander Buch (wie Anm. 26), S. 608-615, 628.

67 Beispielsweise wurden einem am 14. Januar 1643 eingebrachten Gefangenen Fragen nach der Stärke der Infanterie, der Anzahl und den Stellungen der Geschütze und Mörser, der Nachschubsituation und den Arbeiten an den Gräben gestellt. Vgl. StadtA Freiberg, Rep. AA, Abt. IX, Sekt. I, 171, unpaginiert, darin: Aussagen des am 4. Januar 1643 [julian.] eingebrachten Soldaten. Auch über die Verluste der Schweden konnten die Verteidiger Schlüsse ziehen. Vgl. ebd., Aussage eines Gefangenen vom 12. Januar 1643 [julian.].

68 Vgl. ebd., Aussage der Gefangenen vom 26. Januar 1643 [julian.].

69 Vgl. Oraeus, Theatrum Europaeum 4 (wie Anm. 30), S. 917.

70 Vgl. StadtA Freiberg, Abt. I, Ba, 9b, Stadt-Protocolle 1640-1645, S. 292; Möller, Theatrum Freibergense, Ander Buch (wie Anm. 26), S. 611, 659.

71 Vgl. HStA Dresden, 10024 Geheimer Rat (Geheimes Archiv), Loc. 9260/18, fol. 25; Schellhas, Bergleute (wie Anm. 55). 
Johann Georg I. erhielt, größtenteils nur Ermunterungen und Aufforderungen zum ferneren Durchhalten bis zu einer möglichen Befreiung der Stadt. ${ }^{72}$ Dieses Vertrösten zeigt das Dilemma des Kurfürsten auf, denn er hatte keine militärischen Mittel, die Stadt mit eigenen Kräften zu entsetzen. Johann Georg I. war auf die Hilfe des Kaisers angewiesen. Torstensson wusste dies nur zu genau und legte den Verteidigern Freibergs bei seinen Übergabeangeboten immer wieder nahe, sich nicht auf die Kaiserlichen zu verlassen, denn deren Infanterie habe sich zerstreut und deren Kavallerie vagabundiere in Böhmen. ${ }^{73}$

Die Situation im kaiserlichen Heerlager stellte sich etwas anders dar. Schon kurz nachdem sie vom Schlachtfeld bei Breitenfeld entkommen waren, begann die kaiserliche Armeeführung unter Erzherzog Leopold Wilhelm und Feldmarschall Octavio Piccolomini (1599-1656) in Nordböhmen die geschlagenen Reste der Truppen zu sammeln und daraus eine neue Armee zu formen. Im nordböhmischen Rakonitz (Rakovník) versammelte sich bereits im November 1642 ein Großteil der Kavallerie, und Mitte des Monats befanden sich schon wieder 6000 bis 8000 Reiter unter dem Befehl der kaiserlichen Feldherren. ${ }^{74}$

Um eine neue schlagkräftige Armee zu formen, bedurfte es außerdem noch neuen Fußvolkes, für welches jedoch weder die durch Piccolomini in Böhmen gesammelten Versprengten noch die Garnisonen in den Erblanden oder das vom westlichen Kriegsschauplatz nach Böhmen abkommandierte Korps des Grafen Melchior von Hatzfeld (1593-1658) ausreichend waren. Vielmehr war der Kaiser gezwungen, für die Aufstellung der Armee in den Erblanden beim Landtag Gelder für zwei neue Regimenter zu Fuß einschließlich ihres Unterhalts für ein Jahr anzufordern. ${ }^{75}$ Hier machte sich jetzt das Fehlen spanischer Finanzzuwendungen

72 Vgl. StadtA Freiberg, Rep. AA, Abt. IX, Sekt. I, 171, unpaginiert, darin: Schreiben des Kurfürsten vom Januar 1643; HStA Dresden, 10024 Geheimer Rat (Geheimes Archiv), Loc. 9260/18, fol. 4, 6, 25. Gleichzeitig richtete der Kurfürst dringende Bitten an die kaiserliche Armee, die Stadt möglichst schnell zu befreien und damit nicht nur das Kurfürstentum, sondern auch Böhmen und die vitalen Interessen Habsburgs zu schützen. Vgl. z. B. HStA Dresden, 10024 Geheimer Rat (Geheimes Archiv), Loc. 9260/18, fol. 11.

73 Vgl. HStA Dresden, 10024 Geheimer Rat (Geheimes Archiv), Loc. 9260/18, fol. 5; Möller, Theatrum Freibergense, Ander Buch (wie Anm. 26), S. 600.

74 Octavio Piccolomini galt als (Re-)Organisator angeschlagener Heere, so hatte er auch die Reste der Regimenter reformiert, die Torstensson im Sommer 1642 bei Schweidnitz geschlagen hatte. Vgl. Oтto Elster, Piccolomini-Studien, Leipzig 1911. Zugleich wurde versucht, die Disziplin der geschlagenen Truppen mit harter Hand, beispielsweise durch die Dezimierung des Regiments Madlo, welches vom Breitenfelder Schlachtfeld geflüchtet war, zu stärken. Vgl. Oraeus, Theatrum Europaeum 4 (wie Anm. 30), S. 915 f.; Bastian Muth, „damit der Nahme dieses Regiments aus der löblichen Armada vertilget und außgerottet werde“. Eine quellenkritische Untersuchung der Hinrichtung des Regiments Madlo nach der Schlacht bei Breitenfeld im Jahre 1642, in: Ralf Pröve/Carmen Winkel (Hg.), Übergänge schaffen. Ritual und Performanz in der frühneuzeitlichen Militärgesellschaft (Herrschaft und soziale Systeme in der Frühen Neuzeit 16), Göttingen 2012, S. 81-108.

75 Vgl. Oraeus, Theatrum Europaeum 4 (wie Anm. 30), S. 915 f.; HStA Dresden, 10024 Geheimer Rat (Geheimes Archiv), Loc. 9260/18, fol. 15. 
bemerkbar, welche ab 1641 aufgrund der Krise der spanischen Habsburger wegfielen. Dieser Fakt schlug erst jetzt mit einiger Verzögerung durch, da es wegen der Krise der schwedischen Armee nach dem Tod Banérs und der daraus resultierenden Passivität nicht notwendig geworden war, große Geldbeträge zur Aufstellung neuer Truppen aufzubringen. Erst die Niederlagen des Jahres 1642 ließen diese Schwierigkeiten der kaiserlichen Seite sichtbar werden, neues Geld zur Anwerbung neuer Soldaten und zum Führen offensiver Operationen zu beschaffen. ${ }^{76}$

Dennoch vermochte es Piccolomini, innerhalb von sieben Wochen wieder eine einigermaßen schlagkräftige Armee unter die Fahnen zu bringen. Nur darüber, wie diese nun einzusetzen sei, wurde heftig diskutiert. Der Feldmarschall erkannte die strategische Bedeutung der Stadt als Schlüssel für weitere schwedische Operationen gegen Dresden oder gegen Böhmen. So wurde er zu einem Befürworter einer Entsatzoperation, die seiner Meinung nach vordringlich sei, um Böhmen vor einem weiteren Einfall der Schweden zu schützen und nicht Gefahr zu laufen, dass sich Johann Georg I. nach einem Fall Freibergs und einer akuten Bedrohung seiner Residenz in Neutralitätsverhandlungen einließ.77

Nur teilte Wien Piccolominis Einschätzungen nicht uneingeschränkt. Für Ferdinand III. besaßen die Sicherung der Erblande und die Erhaltung der Armee höchste Priorität. Auf die Anfrage seines Bruders Leopold Wilhelm, ob er Freiberg mit ganzer Kraft entsetzen solle, antwortete Ferdinand III. deshalb, dass es zu gefährlich sei, jetzt ein weiteres Zusammentreffen mit den Schweden zu riskieren. Operationen zu einem Entsatz Freibergs oder gar eine Hauptschlacht gegen die Schweden seien zu unterlassen, vielmehr müsse ein eventueller Einfall in Böhmen verhindert werden. ${ }^{78}$ Unterstützung erhielten die Bestrebungen Piccolominis, einen Vorstoß auf Freiberg trotz aller Bedenken durchzuführen, beispielsweise durch den Präsidenten des Hofkriegsrates Heinrich Graf Schlick (1580-1650). Diesen hatte der Feldmarschall ebenfalls von seinen Einschätzungen unterrichtet, und er teilte diese im Hinblick auf die Dringlichkeit der Operation zur Verhinderung einer Neutralität Kursachsens. Nach einem regen Briefwechsel mit Berichten über die Kampfhandlungen und den schon erlittenen Zerstörungen in Freiberg und nach einem intensiven Abwägen entschloss sich Wien schließlich dazu, dem Entsatzvorhaben Piccolominis über Graupen (Krupka) nach Sachsen zuzustimmen.79 So teilte Leopold Wilhelm am 1. Februar 1643 Piccolomini mit,

76 Vgl. Kampmann, Europa und das Reich (wie Anm. 5), S. 142.

77 Vgl. BaD'ura, Vormacht (wie Anm. 60), S. 453 (Dokument 1382, Schreiben Piccolominis an einen spanischen Gesandten aus Pilsen vom 12. Januar 1643). Er folgte damit der Argumentation, die auch Johann Georg I. zur Begründung eines Entsatzes Freibergs vorgebracht hatte. Vgl. HStA Dresden, 10024 Geheimer Rat (Geheimes Archiv), Loc. 9260/18, fol. 1-4, 11.

78 Vgl. Knauth, Aktenstücke (wie Anm. 60), S. 36 (Schreiben Ferdinands III. an Erzherzog Leopold Wilhelm vom 16. Januar 1643).

79 Dass es am Wiener Hof heftige Auseinandersetzungen von Gegnern und Befürwortern der Operation gegeben hatte, bezeugen die Schreiben Schlicks, in denen er sich unter anderem darüber beschwert, dass man nicht schon früher, nämlich Anfang Januar, auf 
dass der Kaiser die Konzentration der Kavallerie bei Brüx (Most) billige und die benötigte Infanterie auf dem Weg sei, um mit den Schweden zahlenmäßig gleichzuziehen. Der Feldmarschall sollte jedoch bis zu deren Eintreffen weiter abwarten und bis dahin die Freiberger vertrösten. Im Falle einer Kapitulation Freibergs vor dem Eintreffen der Infanterieregimenter sei es jedoch die vordringlichste Aufgabe, Böhmen vor den Schweden zu schützen und mit der Operation die Gesamtlage nicht $\mathrm{zu}$ gefährden. ${ }^{80}$

Hierin zeigt sich die vorsichtige Vorgehensweise der kaiserlichen Seite nach den erlittenen Niederlagen. Ferdinand III. war nicht gewillt, für die sächsische Stadt die Armee oder gar Böhmen aufs Spiel zu setzen. Infolgedessen musste Piccolomini den Kurfürsten und die Verteidiger zunächst weiter vertrösten. In seinem Schreiben vom 28. Januar 1643, das von einem Bergmann in die Stadt geschleust wurde, berichtete er, dass die Kavallerie bereits versammelt war und man nur noch auf das Eintreffen der Artillerie und weiterer Infanterie warte, um dann den Eingeschlossenen mit 7000 bis 8000 Mann zu Fuß und 12000 Reitern zu Hilfe zu kommen. Bis dahin mussten die Verteidiger durchhalten und der Pendelbriefverkehr zwischen dem Lager Piccolominis und den Belagerten in Freiberg über ausgeschickte Bergleute aufrechterhalten werden. ${ }^{81}$

Im Februar trat die Belagerung in eine neue Eskalationsstufe ein. Nun intensivierten die Schweden ihrerseits die Bemühungen zur Einnahme Freibergs mit der Wiederaufnahme des intensiven Beschusses der Befestigungsanlagen sowie dem Abfeuern von Brandgeschossen, sogenannten Feuerballen. ${ }^{82}$ Am 16. Februar 1643 machte Torstensson schließlich ein weiteres Angebot mit dem Anreiz, dass mit einer Übergabe die zunehmende Verheerung des Umlandes verhindert werden könne, da die schwedischen Soldaten sich während der Belagerung aus dem Land heraus versorgen müssten. Doch der Kommandant lehnte abermals mit Verweis auf seine Befehle und in der Hoffnung, bis zum Eintreffen Piccolominis die Stadt halten zu können, ab, auch als der Feldmarschall drohen ließ, die Stadt ohne Rücksicht auf die Bevölkerung zu zerstören. ${ }^{83}$

Dass jene Hoffnung des Kommandanten nicht völlig unbegründet war, zeigten die Entwicklungen, die sich unterdessen im Lager der Kaiserlichen zugetragen hatten. Noch am 13. Februar 1643 hatte Piccolomini Leopold Wilhelm abermals

ihn gehört habe und mit dem Inmarschsetzen der mährischen Regimenter die Stadt entsetzt hätte. Vgl. Knauth, Aktenstücke (wie Anm. 60), S. 37 f. (Schreiben Heinrich Schlicks an Piccolomini vom 16. Januar 1643 und 29. Januar 1643), 40 (Schreiben Heinrich Graf Schlicks an Piccolomini aus Wien vom 21. Februar 1643).

80 Vgl. Knauth, Aktenstücke (wie Anm. 60), S. 38 f. (Schreiben Leopold Wilhelms an Piccolomini vom 1. Februar 1643; Schreiben Leopold Wilhelms an Piccolomini aus Wien vom 10. Februar 1643).

81 Vgl. HStA Dresden, 10024 Geheimer Rat (Geheimes Archiv), Loc. 9260/18, fol. 74-77; Möller, Theatrum Freibergense, Ander Buch (wie Anm. 26), S. 619.

82 Vgl. HStA Dresden, 10024 Geheimer Rat (Geheimes Archiv), Loc. 9260/18, fol. 34; Möller, Theatrum Freibergense, Ander Buch (wie Anm. 26), S. 629-632.

83 Vgl. Möller, Theatrum Freibergense, Ander Buch (wie Anm. 26), S. 632-634. 
aufgefordert, ihm den angeforderten Marschbefehl in Richtung Freiberg zu geben. Hierbei machte er deutlich, ein Fall der Stadt bedeute, dass die Schweden militärische Operationsfreiheit sowohl in Richtung Meißen als auch in die Oberpfalz bekämen und damit auch die Vereinigung mit den Franzosen zu befürchten sei. ${ }^{84}$ Ferdinand III. und der Erzherzog erteilten daraufhin ihrem Feldmarschall den Einsatzbefehl, dem Piccolomini auch schnell und gewissenhaft nachkommen wollte. Er wusste durch die Botenverbindung nach Freiberg und durch Vorstöße seiner leichten Kavallerie über den Erzgebirgskamm, dass die Belagerer ihre Anstrengungen intensiviert und die Belagerten einen zunehmend schweren Stand hatten. ${ }^{85}$ In einem am 15. Februar 1643 nach Freiberg abgeschickten Papier konnte der Feldmarschall den Verteidigern in Aussicht stellen, in sechs bis acht Tagen auf dem Kamm des Erzgebirges zu sein. Bis dahin müsse man sich aber noch versuchen zu halten. ${ }^{86}$

Die Verteidiger hatten im Vertrauen auf die Zusagen Johann Georgs I. und Piccolominis in der Ratssitzung vom 8. Februar noch einmal bekräftigt, sich weiter verteidigen zu wollen. ${ }^{87}$ Piccolominis Zusage stärkte diese Bereitschaft nun weiter, obwohl sich die militärische Lage in jenen Tagen noch einmal verschärfte und es zunehmend schwierig war, Torstenssons Truppen vom Durchbruch in die Stadt abzuhalten, auch wenn es diesen nicht gelang, eine Bresche für einen schon vorbereiteten Hauptsturm zu schlagen. ${ }^{88}$

Als es am 25. Februar 1643 immer noch keine Nachrichten oder Anzeichen für die Annäherung der Kaiserlichen gab, versuchten die Verteidiger, durch Verhandlungen noch einmal Zeit zu gewinnen. Jedoch wurden diese von schwedischer Seite abgebrochen und ein Übergabeangebot zu Torstenssons Bedingungen formuliert, da Freiberg nur eine Landstadt und keine Festung sei. Der Stadtkommandant lehnte diese jedoch $a b$, auch wenn es bisher nur Gerüchte vom Nahen der Entsatztruppen gab. Gewissheit darüber erhielten die Verteidiger in der folgenden Nacht, als die von Piccolomini angekündigten Feuer als Zeichen für dessen Auf-

84 Vgl. Bad’ura, Kampf (wie Anm. 60), S. 458 (Dokument 1395: Schreiben Piccolominis an Leopold Wilhelm aus Brüx vom 13. Februar 1643).

85 Vgl. BaD’ura, Kampf (wie Anm. 60), S. 458 (Dokumente 1396, 1397: Zwei Schreiben Piccolominis an Leopold Wilhelm aus Brüx vom 15. Februar 1643).

86 Vgl. StadtA Freiberg, Rep. AA, Abt. IX, Sekt. I, 171, unpaginiert, darin: Schreiben Piccolominis an von Schweinitz aus Brüx vom 15. Februar 1643. Inhaltlich in etwa gleich auch an Johann Georg I. Vgl. HStA Dresden, 10024 Geheimer Rat (Geheimes Archiv), Loc. 9260/18, fol. 74 .

87 Vgl. StadtA Freiberg, Abt. I, Ba 9b, Stadt-Protocolle 1640-1645, S. 293.

88 Vgl. HStA Dresden, 10024 Geheimer Rat (Geheimes Archiv), Loc. 9260/18, fol. 44-47, 51-53; Möller, Theatrum Freibergense, Ander Buch (wie Anm. 26), S. 635-642. Mit dem Beginn des Vormarschs der kaiserlichen Armee nach Sachsen intensivierte sich nun der Briefverkehr zwischen Johann Georg I. und Piccolomini, sodass bis zur Befreiung Freibergs beinahe täglich über Fortschritte und zu leistende Unterstützung durch Kursachsen korrespondiert wurde. Vgl. HStA Dresden, 10024 Geheimer Rat (Geheimes Archiv), Loc. 9260/18, fol. 54-83. 
marsch wahrgenommen werden konnten. ${ }^{89} \mathrm{Um}$ das weitere Vordringen der Kaiserlichen zu blockieren, schickte Torstensson am Morgen des 26. Februar 1643 diesen seine Reiterei entgegen und ließ währenddessen die Infanterie gegenüber dem Peterstor sammeln. Zwischen acht und neun Uhr zeitigte die Arbeit der schwedischen Mineure eine verheerende Wirkung, da eine große Mine unter der Hauptmauer Freibergs erfolgreich zur Explosion gebracht und diese dadurch auf mehreren zwanzig Ellen total niedergeworfen wurde. ${ }^{90}$

Aufgrund der veränderten Lage ließ Torstensson wiederum die Übergabe der Stadt fordern, dabei die Gegenwehr der Garnison rühmen und nochmals einen guten Accord anbieten, auch wenn nach der Einebnung der Mauer die Stadt bereits sturmreif sei. Die Besatzung schlug das Angebot erneut mit dem Verweis auf den nahen Entsatz aus, obwohl der Schwede deutlich machte, dass er glaube, Piccolomini werde schwerlich eine bataille hazardierten, und umb der Stadt willen das Römisch Reich in Gefabr setzen. ${ }^{91}$ Auch zwei weitere Versuche, eine Übergabe anzubieten, scheiterten, der letzte soll schließlich mit den Worten der Accord sey gemacht, die Schweden sollen aus der Stadt, undt die sächsischen wollen drinnen bleiben $^{92}$ abgewiesen worden sein. Infolgedessen befahl der Feldmarschall die Bereitstellung zum Generalsturm, doch stattdessen erfolgte während der Nacht der Abtransport des Belagerungsgerätes und der endgültige Aufbruch des schwedischen Heeres am 27. Februar 1643 bei Tagesanbruch. ${ }^{93}$

Wohl der wichtigste Grund für den Abbruch des Generalsturms und für den überraschend schnellen Aufbruch der Schweden war der rasche Vormarsch der Entsatztruppen. Nach der kaiserlichen Freigabe und dem Vorrücken der leichten Kavallerie nach Sachsen war Piccolomini mit der Hauptmasse seiner Truppen gefolgt. Am 16. Februar war man in Brüx (Most) aufgebrochen und erreichte nun nach der schwierigen Passage des Erzgebirgskammes am 26. Februar 1643 Glashütte, wo Piccolomini von Gefangenen seiner Kroaten vom bevorstehenden Generalsturm erfuhr. Daraufhin sandte er nochmals nach Dresden, um bei Johann Georg I. um Unterstützung auf der letzten Etappe bis Freiberg nachzusuchen. ${ }^{94}$ Außerdem kommandierte der Feldmarschall die Kavallerieeinheiten voraus, um die Schweden in Scharmützel zu verwickeln und sie so vom Generalsturm abzuhalten. Er selbst wollte mit der Hauptmasse im Morgengrauen des 27. Februar weiter nach Freiberg vorrücken. ${ }^{95}$

89 Vgl. MöLler, Theatrum Freibergense, Ander Buch (wie Anm. 26), S. 644-646.

90 Vgl. ebd., S. $648 \mathrm{f}$.

91 Ebd., S. 649.

92 StadtA Freiberg, Abt. I, Ba 9b, Stadt-Protocolle 1640-1645, S. 295.

93 Vgl. StadtA Freiberg, Rep. AA, Abt. IX, Sekt I, 171, unpaginiert, Bericht zum Generalsturm; Möller, Theatrum Freibergense, Ander Buch (wie Anm. 26), S. 648651.

94 Vgl. HStA Dresden, 10024 Geheimer Rat (Geheimes Archiv), Loc. 9260/18, fol. 73-83.

95 Vgl. Knauth, Aktenstücke (wie Anm. 60), S. 40 (Schreiben Leopold Wilhelms an Piccolomini aus Wien vom 25. Februar 1643); BAD'URA, Kampf (wie Anm. 60), S. 459 (Dokument 1402: Schreiben Piccolominis an Leopold Wilhelm aus Glashütte vom 
Im Laufe des Vormittags erreichten schließlich die ersten kaiserlichen Einheiten die Stadt, nachdem Torstensson zunächst seine Artillerie und die Bagage und anschließend die Infanterie und Kavallerie abgezogen hatte. Am 28. Februar 1643 traf Piccolomini mit seinem Stab ein, wurde vom Kommandanten von Schweinitz durch die Stadt geführt, besuchte die kurfürstliche Grablege und wurde vom Rat und den Beamten der Stadt empfangen. Bei der Besichtigung der Stadt zeigte sich der Feldmarschall erstaunt, dass sich die Stadt trotz dieser großen Schäden so lange habe halten können. ${ }^{96}$

Der Erfolg war jedoch für die Stadt und ihre Bewohner teuer erkauft worden; nicht nur, dass die Verteidigungsanlagen rings um das Peterstor einer Trümmerlandschaft glichen, auch viele andere Gebäude der Stadt hatten durch den Beschuss teils erhebliche Schäden davongetragen. Überdies war die unmittelbare Umgebung der Stadt verheert. So musste in Folge der Belagerung das Hospital geschlossen und ein großer Teil der Bergbauinfrastruktur wiederaufgebaut werden. Innerhalb der Mauern sah die Situation nicht weniger trostlos aus. In den Tagen direkt nach der Aufhebung der Belagerung läuteten nahezu ohne Unterbrechung die Kirchenglocken und es wurden die Toten begraben. ${ }^{97}$ Die Belagerung hatte mindestens 75 Soldaten und Angehörigen des Defensionswerkes das Leben gekostet, 175 waren verwundet worden. Doch auch die Bewohner Freibergs hatten einen hohen Blutzoll entrichtet, denn allein während der Kampfhandlungen verloren über 50 Zivilisten ihr Leben. ${ }^{98}$

\section{Rezeption und Bedeutung der Belagerung}

Torstenssons Armee zog sich geordnet, aber dennoch angeschlagen von der Stadt zurück. Nach Aussagen entlaufener Gefangener hatten die Schweden vor der Stadt an die 3000 Mann an Entflohenen, Verwundeten und Toten zu beklagen. ${ }^{99}$ Andere Quellen sprechen von geringeren Verlusten. So gibt eine der Relationen aus dem Jahr 1643 die Zahl der Gefallenen und Entlaufenen bei den Schweden mit 1500 und die Zahl derer, welche durch Ausfälle der Verteidiger gefangen wurden, mit 60 Mann an. ${ }^{100}$ Der Feldmarschall schonte also seine Truppen nicht und ließ seine

26. Februar 1643; Schreiben Leopold Wilhelms an Piccolomini aus Wien vom 25. Februar 1643).

96 Vgl. Möllek, Theatrum Freibergense, Ander Buch (wie Anm. 26), S. 654-656.

97 Vgl. StadtA Freiberg, Rep. AA, Abt. IX, Sekt. I, 171, unpaginiert, Schreiben eines Bürgers vom 18. Februar 1643 [julian.].

98 Vgl. Schellhas, Bergleute (wie Anm. 55), S. 167. Zudem lässt sich für das Jahr 1643 insgesamt eine Steigerung der Verstorbenenzahl feststellen. Vgl. StadtA Freiberg, Abt I, Ba 9b, Stadt-Protocolle 1640-1645, S. 287, 486, 759, 938.

99 Vgl. Möller, Theatrum Freibergense, Ander Buch (wie Anm. 26), S. 655.

100 Vgl. Eigentlicher Bericht von der Belagerung der Churfürstlichen Bergstadt Freyberg in Meissen / welche von den Schwedischen General-Feldmarschall Torstensohn 7. Wochen vnd 3. Tage belägert gewest [...], o. O. 1643. 
Soldaten auch nach steigenden Verlusten im Verlauf der Belagerung immer energischer gegen Freiberg anrennen. Doch sie vermochten es nicht, die Stadt rechtzeitig einzunehmen, denn bei seiner Machtdemonstration hatte Torstensson vor allem nicht mit einer schnellen Reorganisation und einem raschen Vormarsch der Truppen Piccolominis gerechnet. Darüber hinaus waren aber auch die spezifischen Faktoren der Belagerung Freibergs ursächlich für das Scheitern der Schweden. Zum einen mussten die bisher so erfolgreichen schwedischen Belagerer ihre Arbeit unter winterlichen Bedingungen ausführen, zum anderen trafen sie in der untertunnelten Bergbauregion auf ungünstige topografische Gegebenheiten, welche die Angreifer hemmten und die sich die Verteidiger nutzbar machen konnten. Hier sei vor allem auf die Aufrechterhaltung der Kommunikation der Stadt mit dem Kurfürstenhof und dem kaiserlichen Heerlager durch die Botengänge der Bergleute sowie auf deren geschicktes Verderben der schwedischen Minengänge hingewiesen.

Mit dem Abzug von Freiberg war Torstenssons Vorgehen, Johann Georg I. im übertragenen Sinne militärisch seine Instrumente vorzuführen und sukzessive diese Daumenschrauben anzuziehen, ihm dabei gleichzeitig immer auch die Möglichkeit eines Auswegs durch Verhandlungen offenzulassen, zunächst gescheitert. So ließ der schwedische Feldmarschall auch den Gesprächskanal über den in Halle residierenden Herzog August von Sachsen zunächst wieder versiegen, da er feststellen musste, dass seit dessen [Augusts] ankunfft in Hall, von des Churfürsten näberer Accomodation nichts weiters verspüret worden, vielmehr derselbe auf voriger Intention beharret, ja schier noch tieffer mit dem Feinde eingestiegen. 101

Die kursächsische Seite schöpfte hingegen aus der erfolgreich ausgestandenen Belagerung Freibergs wieder Vertrauen in den kaiserlichen Verbündeten, wie auch die kaiserliche Seite insgesamt an Selbstvertrauen und Hoffnung auf eine abermalige Verbesserung der militärischen und diplomatischen Lage zu ihren Gunsten gewonnen hatte. Dies entsprach auch der Einschätzung des Feldmarschalls Piccolomini, der bereits vor dem Vorrücken seiner Truppen zum Ausdruck brachte, dass ein Erfolg der Entsatzoperation viel eher psychologisch denn militärisch bedeutsam sein würde. Anstatt zu zaudern und zu taktieren, galt es, mit einem energischen Vorstoß nach der verheerenden Niederlage bei Breitenfeld die eigene Handlungsfähigkeit unter Beweis zu stellen und so die eigene Position zu festigen. ${ }^{102}$

Wie bedeutsam der Erfolg vor Freiberg für das kaiserliche Lager war, kann auch an den Glückwünschen und Ehrungen für die Verteidiger abgelesen werden. Nicht nur der kaiserliche Feldherr sah im Aushalten der Verteidiger ein leuchtendes Beispiel, ${ }^{103}$ sondern auch Ferdinand III. selbst übermittelte in seinem Schrei-

101 Chemnitz, Krieg 4/3 (wie Anm. 43), S. 34.

102 Vgl. Bad'ura, Kampf (wie Anm. 60), S. 458 (Dokument 1398: Schreiben Piccolominis an Marquis de la Fuente aus Brüx vom 16. Februar 1643).

103 Vgl. Möller, Theatrum Freibergense, Ander Buch (wie Anm. 26), S. 661. Welchen Stellenwert der Erfolg für Piccolomini hatte, verdeutlicht die Tatsache, dass er bei dem 
ben vom 8. März 1643 an den Kommandanten, den Bürgermeister und den Rat Freibergs Lob und Anerkennung, sah er doch in der Verteidigung Freibergs ein Vorbild für andere Städte des Reiches, denen ein ähnliches Schicksal drohte. ${ }^{104}$ Auch für andere Verbündete des Kaisers war die Befreiung Freibergs ein Hoffnungsschimmer und ein Schritt auf dem Weg zu einer abermaligen militärischen Wende zugunsten der Kaiserlichen. So gratulierte beispielsweise auch der Kölner Kurfürst Ferdinand von Bayern (1577-1650) Piccolomini zu seinem erfolgreichen Vorstoß.105

Für die Bedeutung der Ereignisse um die sächsische Berghauptstadt spricht zudem auch die Thematisierung in den zeitgenössischen Druckmedien.106 Beispielsweise lassen sich für das Jahr 1643 verschiedene Relationen über die Belagerung nachweisen, die nicht nur in ihrem Umfang, sondern teilweise auch in ihren Aussagen differieren. ${ }^{107}$ Am weitesten verbreitet ist wahrscheinlich jene Relation, welche, in Freiberg gedruckt und zeitnah zum Abzug der Schweden erschienen, dem Freiberger Chronisten und Arzt Andreas Möller (1598-1660) zuzuschreiben ist. Hier lässt sich das Interesse der Verteidiger erkennen, ihre Sicht der Ereignisse möglichst schnell zu verbreiten und damit die Deutungshoheit über das Ereignis zu erlangen. ${ }^{108}$ Die Drucke, die mutmaßlich von kaiserlich-kursächsischer Seite publiziert wurden, stellen dann neben dem Bericht der Ereignisse vor allem auch den Zusammenhalt von Kommandanten, Rat und Bürgerschaft und den Erfolg als

niederländischen Schlachtenmaler Pieter Snayers ein Gemälde zum Abzug der Schweden von Freiberg in Auftrag gab. Vgl. Walter F. Kalina, Die Piccolominiserie des Pieter Snayers. Zwölf Schlachtengemälde im Wiener Heeresgeschichtlichen Museum, in: Viribus Unitis. Jahresbericht 2005 des Heeresgeschichtlichen Museums, Wien 2006, S. 87-116, hier S. 110-112. Zur Schlachtenmalerei des 17. Jahrhunderts: MatTHiAS Pfaffenbichler, Das frühbarocke Schlachtenbild. Vom historischen Ereignisbild zur militärischen Genremalerei, in: Klaus Bußmann (Hg.), 1648. Krieg und Frieden in Europa, Textband II: Kunst und Kultur, S. 493-500.

104 Vgl. Möller, Theatrum Freibergense, Ander Buch (wie Anm. 26), S. 665-668.

105 Vgl. Knauth, Aktenstücke (wie Anm. 60), S. 40 (Schreiben des Kurfürsten von Köln an Piccolomini vom 13. März 1643); Möller, Theatrum Freibergense, Ander Buch (wie Anm. 26), S. 660 f.

106 Vgl. Burkhardt, Dreißigjähriger Krieg (wie Anm. 5), S. 225-229; Ulrich Rosseaux, Kipper und Wipper als publizistisches Ereignis (1620-1626). Eine Studie zu den Strukturen öffentlicher Kommunikation im Zeitalter des Dreißigjährigen Krieges, Berlin 2001, S. 23-40.

107 Kurtzer und gründlicher Bericht / Von der denckwürdigen Belägerung der Churf. Sächs. freyen Berg=Stadt Freiberg [...] Durch Einem Mitbelägerten, o. O. 1643; Eigentlicher Bericht (wie Anm. 100). Darüber hinaus Wiederauflage bzw. Neudruck: Gründliche und eigentliche Relation, von der Belagerung der Stadt Freyberg, in: Freybergische Stadt=Jubel=Acta (wie Anm. 4), S. 98-112.

108 Vgl. Andreas Möller, Gründliche und außführliche Relation, Von der sehr harten / weit beschriehenen und denckwürdigen Plocquada und Belägerung der Churf. Sächs. ältesten Freyen Bergkstadt Freybergk in Meissen [...], Freiberg 1643. So auch der Grundton beim Exulanten Hironymus Wesner, der dem Rat eine schnelle Veröffentlichung einer Relation empfiehlt. Vgl. StadtA Freiberg, Rep. AA, Abt. IX, Sekt. I, 172/2, unpaginiert, Schreiben des Exulanten Hieronymus Wesner vom 22. April 1643 [julian.] an den Rat. 
besondere Gnade Gottes in den Vordergrund. ${ }^{109}$ Eine andere Interpretation lässt sich vor allem im Theatrum Europaeum nachweisen, dessen vierter Band zeitnah $\mathrm{zu}$ den Ereignissen erschien und der in seiner Interpretation der Belagerung eher der schwedischen Seite zugeneigt scheint. ${ }^{110}$

Außer diesen Auswirkungen auf die diplomatische wie publizistische Ebene des Krieges hatte die Belagerung Freibergs in militärischer Hinsicht keinen wesentlichen Umschwung zur Folge. Sie fügt sich gerade idealtypisch in die Endphase des Krieges ein, in welcher die Kriegsparteien selbst kleinen Erfolgen große Bedeutung zumaßen, entscheidende Umschwünge zugunsten des kaiserlichen Lagers aber ausblieben. Zwar hatte die schwedische Armee empfindliche Verluste davongetragen und an Schlagkraft verloren, das kaiserliche Heer war jedoch nicht imstande, diese Lage auszunutzen. ${ }^{111}$ Vielmehr verlagerten sich die Kampfhandlungen nach Schlesien, bevor Torstensson im Spätjahr 1643 den Kriegsschauplatz in Richtung Dänemark verließ, um dort gegen den dänischen König zu kämpfen, letzteren von einem Eingreifen auf Seiten des Kaisers abzuhalten und so die schwedische Vormacht im Ostseeraum zu festigen sowie schließlich auf dem Westfälischen Friedenskongress noch machtvoller auftreten zu können. ${ }^{112}$

Im Hinblick auf die Rolle Kursachsens in der Endphase des Dreißigjährigen Krieges kann festgehalten werden, dass es nur noch über wenig diplomatischen Spielraum und über limitierte militärische Mittel verfügte. Man hatte nur eine

109 Vgl. Möller, Relation (wie Anm. 108); Apianus Apiano, Gott mit uns! Schwedischer Abzugk von Freybergk, o. O. 1643; David Schirmer, Jesu Christi Triumph: So den Römischen ubertroffen / Denen Freybergern aber geholffen, Freiberg [1643]. Auf diesen Deutungsmustern aufbauend die städtische Erinnerungskultur: Relation Torstensohnischer Belagerung der Stadt Freybergk, Freiberg 1674; Samuel Moller, Am Tage Concordiae ward bey dem sonst gewöhnlichen Richterischen Actu das Programma, de Fama, ausgesetzt / und diese fromme Pflegerin der Tugend dem 17. Febr. 1723 Dagleich vor 80. Jahren ein erhitzter Feind die harte zwey monathliche Belagerung der alten löblichen freyen Berg=Stadt Freyberg auffzuheben genöthigt worden [...], Freiberg 1723; Die Feier des 17. Februar 1843 und des 11. und 12. August $1844 \mathrm{zu}$ Freiberg. Nebst einer kurzen geschichtlichen Einleitung: die Jahre 1643 und 1743, Freiberg 1844. Am deutlichsten in der Symbolik des Schwedendenkmals Eduard Heuchlers und im Rahmen der Feierlichkeiten zum 250. Jubiläum: GERLACH, Feier der Erinnerung (wie Anm. 10), S. 1-8; StadtA Freiberg, Rep. A, Abt. I, Sekt. IX, Nr. 192.

110 Vgl. Oraeus, Theatrum Europaeum 4 (wie Anm. 30), S. 916 f. Ebenso in der im schwedisch besetzen Leipzig erschienenen Messrelation: Gregor Wintermonat, CONTINUATIO XII/I: Der Zehnjährigen Historischen Relation: [...], Leipzig 1643, S. 117-124. Kritik am Theatrum Europaeum bei MöLler, Theatrum Freibergense, Ander Buch (wie Anm. 26), S. 594. Bemerkenswert ist, dass im fünften Band des Theatrum Europaeum die Belagerung Freibergs nochmals thematisiert wurde. Hier war wahrscheinlich nun die Relation Möllers Grundlage der Beschreibung. Vgl. Johann Peter Lotichius, Theatrum Europaeum, 5. Teil: [...] vom Jahr 1643 biß ins 1647. Jahr allseits begeben und verlaufen, Frankfurt am Main 1651, S. 21-28.

$111 \mathrm{Vgl}$. Knauth, Aktenstücke (wie Anm. 60), S. 43 (Instruktion Johann Georgs I. durch den kaiserlichen Generalwachtmeister Trenditzsch).

112 Zum Feldzug gegen Dänemark vgl. Reвiтsch, Gallas (wie Anm. 39), S. 251-298; JörgPeter Findeisen, Axel Oxenstierna. Architekt der schwedischen Großmacht-Ära und Sieger des Dreißigjährigen Krieges, Gernsbach 2007, S. 387-397. 
kleine Garnison zur Verteidigung Freibergs bereitstellen können, und auch wenn diese sich zwar tapfer verteidigte, so war Johann Georg I. für eine erfolgreiche Befreiung essenziell auf die Waffenhilfe des Kaisers angewiesen. Ohne diese Unterstützung wäre wohl auch Freiberg wie zuvor Leipzig verloren gegangen, der Weg nach Dresden wäre offen und ein Ausscheiden der Sachsen aus dem Krieg nur die logische Konsequenz gewesen. Dies war auch den Verbündeten gegenwärtig, die durch die Befreiung Freibergs den Abfall des Mitkonstrukteurs des Prager Friedens und damit den Erfolg der schwedischen Strategie der schrittweisen Demontage des Prager Militärsystems im Wechselspiel von militärischem Druck und diplomatischen Angeboten vorerst verhindern konnten. Mit dem erfolgreichen Aushalten der Verteidiger, dem glücklichen Vordringen der kaiserlichen Armee und schließlich dem Abmarsch der Schweden nach Dänemark verringerte sich noch einmal der Druck auf Johann Georg I., was schließlich ausschlaggebend dafür war, dass dieser noch weitere knapp zweieinhalb Jahre als aktiver Verbündeter des Kaisers im Kriegsgeschehen verblieb. Es gelang dem sächsischen Kurfürsten sogar, während der Abwesenheit der schwedischen Hauptarmee vom sächsischen Kriegsschauplatz im Jahre 1644 nochmals Städte wie Chemnitz, Grimma oder Rochlitz zurückzuerobern. ${ }^{113}$ Mit der Rückkehr von Torstenssons Armee im Spätjahr 1644 und der endgültigen Zerschlagung des kaiserlichen Heeres bei Janckau am 6. März 1645 zeitigte die schon 1642/43 angewandte Strategie jedoch durchschlagende Erfolge. Torstensson konnte den sächsischen Kurfürsten so weit bedrängen, dass dieser sich gezwungen sah, die diplomatischen Unterhandlungen, welche mit der Belagerung Freibergs zunächst abgebrochen waren, wieder aufzunehmen. Diese endeten schließlich mit dem Waffenstillstand von Kötzschenbroda vom 6. September 1645 und dem faktischen Ausscheiden Kursachsens aus dem Krieg, da die Regelungen des Waffenstillstandes im Wesentlichen im Frühjahr 1646 nach weiteren Verhandlungen in Eilenburg bis zum Kriegsende verlängert wurden. ${ }^{114}$

113 Vgl. Sennewald, Kursächsisches Heer (wie Anm. 7), S. 433-445.

114 Vgl. HStA Dresden, 10024 Geheimer Rat (Geheimes Archiv), Loc. 9261/19; Loc. $9261 / 20$. 